THE JOURNAL OF TRANSPORT AND LAND USE http://jtlu.org

VOL. 9 NO. 1 [2016] pp. 65-96

JTLU

\title{
Shape grammars overview and assessment for transport and urban design: Review, terminology, assessment, and application
}

\author{
Basil Janis Vitins \\ Institute for Transport Planning \& Systems, ETH Zurich \\ basil.vitins@ivt.baug.ethz.ch \\ Kay W. Axhausen \\ Institute for Transport Planning \& Systems, ETH Zurich \\ axhausen@ivt.baug.ethz.ch
}

\begin{abstract}
Shape grammars for urban design have attracted much interest in research and practice. Transport and urban planners increasingly deploy shape grammars, especially in simulations and procedural models. Shape grammars have multiple advantages due to their interdisciplinary and straightforward approach and low computational requirements. In addition, a rulebased design method and underlying fundamental research knowledge can potentially support future planning and design guidelines for handbooks and norms. However, little is known about the effectiveness of shape grammars in transport networks and urban environments. The proposed methodology aims at a future development of a robust and effective language for sustainable urban development. The theory of different fields is consolidated for a general grammar definition. Grammars require specified and corresponding objectives and application specifications for enhanced implementation. The proposed methodology for grammar rule assessment is based on elasticities to gain more insights in the effect of the rules. Elasticities allow comprehensive comparisons and verification between grammar rules. The paper reviews and highlights the key achievements and applications of shape grammars in cognate fields of science. Terminology sheds light on the definitions of most relevant terms including a general definition for grammar rules embedded in the language context. The paper differentiates methodological approaches in grammar design assessment and emphasizes a standardized approach for shape grammar definitions. The paper concludes with a detailed example for grammar rule assessment and potential future research.
\end{abstract}

Article History:

Received: November 30, 2013

Received in revised

form: August 28, 2014

Accepted: October 18, 2014

Available online: May 16, 2016

\section{Introduction}

Throughout history, each era developed specific transport network patterns and characteristics,

Copyright 2016 Basil Janis Vitins and Kay Axhausen.

doi: $10.5198 /$ jtlu.2016.620

ISSN: 1938-7849 | Licensed under the Creative Commons Attribution - NonCommercial License 3.0.

The Journal of Transport and Land Use is the official journal of the World Society for Transport and Land Use (WSTLUR) and is published and sponsored by the University of Minnesota Center for Transportation Studies. This paper is also published with sponsorship from WSTLUR and the Institutes of Transportation Studies at the University of California, Davis, and the University of California, Berkeley. 
which were designed to meet specific requirements using then-available technologies. It can be easily seen that the transport network patterns of one era replaced those of the prior era and that many patterns were passed on to following generations, surviving as urban plans. Medieval fabrics contrast with baroque layouts and gridirons, and these differ again from garden cities, modernist layouts, and dendritic lollipop networks, which are based on tree-like layouts with high interior densities. Many of these patterns have been and will continue to be bequeathed to future generations.

However, in the near future, urban agglomerations and systems will grow rapidly around the globe (World Bank 2013), requiring new built environment and transport systems to meet the needs and requirements of new urban areas.

Despite various research and applied research, a consensus on best-practices is missing in urban network design. The optimal urban design for economical, societal, and environmental needs remains contentious.

Existing academic literature shows that transport planning, architecture, and urban planning-as well as graph-based and operations research approaches-have contributed to urban network design. These four major research strands are described below with examples, each aiming at the overarching goal of urban network design.

1. Transport planning in a wider sense focuses on scenario development and comparison, covering economics (Venables 2007), risk and resilience (Erath et al. 2009; Helbing 2013), energy supply in spatial developments (Keirstead and Shah 2011), and corresponding travel behavioral studies (Bhat and Guo 2007). Marshall (2005) focuses on streets and patterns and underlying grammar rules, such as those for road type choice and design. Van Nes (2003) evaluated and optimized road and public transportation networks and characteristics (such as road spacings) and densities.

2. Architectural and urban planning perspectives are provided by Alexander et al. (1977), Southworth and Ben-Joseph (2003), Marshall (2005), and others. These sources present, based on profound expertise and knowledge, qualitative urban designs for a functional, livable, and economic city. An increasing number of urban models and simulations have been applied in recent years (ESRI 2012; UrbanVision 2012).

3. Graph-based and statistical analyses evaluate urban networks from a graph perspective and might include topological evaluations. Evaluations are provided by Cardillo et al. (2006) and Xie and Levinson (2011), who compared transport network topologies, various network types, and historical developments. Space syntax comprises a set of methods and techniques to analyze spatial arrangements (Hillier et al. 1976). Batty (2008) evaluated network sizes, morphology, and geometry of various cities worldwide.

4. The operations research community has focused on network design and optimization for a long time, and covers multiple network types-e.g., information, water supply, logistics, and transportation (Goldberg 2002; Hillier and Lieberman 2005; LeBlanc 1975). In transportation especially, the bi-level optimization of networks was applied in an increasing number of applications.

Summing up, network design remains contentious despite research achievements and the relatively straightforward underlying definition of networks as (planar) graphs based on nodes and edges (Clark and Holton 1991).

There is evidence that shape grammars are efficient tools for network design and are able to overcome various difficulties in designing urban areas. Shape grammars consist of a finite and defined set of syntactic rules. The syntax consists of the rules to govern distinct elements, such as words in linguistics or elementary building blocks in urban planning. The expression is widely used in computer science to describe the combination of elements to build a structured source code. Also, architects and urban planners often refer to syntax and assemble urban elements according to distinct rules. In this paper, it is claimed that syntax alone is insufficient to generate a reasonable outcome. It is claimed that grammars further include application specifications, which resemble semantics. Application specifica- 
tions are instructions for efficient applications. Moreover, they can refer to background information and therefore contain information about the origin of the corresponding rules. This paper sheds more light on the theoretical requirements for grammars and their efficient and meaningful applications.

A large number of researchers and planners have applied shape grammars to an increasing extent in recent years for urban simulations and also in applications of cognate fields such as architecture and computer simulation. In some research, the rules might be stated and formulated explicitly as a result. In other research, the results are not declared as ruled, but they could be interpreted as such.

In transport planning, van Nes (2003) and Yerra and Levinson (2005) contributed to a more rulebased understanding of transport network design. They evaluated the block spacing and road type distribution of a given network design. Norms and design guidelines resemble grammar rules and are provided by handbooks (AASHTO 2004; FGSV 2008; IHT 1997; VSS 1994). Handbooks play a key role in planning new or improving existing sites, and they apply planning rules to a certain extent, to define recommendations more specifically.

In urban planning, rules or codes are developed for consistent design, for specific purposes (such as urban densities), and to improve the livability, orientation, and perception of a city. Kaisersrot (2011) and "SmartCode" (Duany et al. 2009) are two example implementations based on specific rules. Moreover, the movement of New Urbanism often describes its ideas in codes (Dutton 2000; Haas 2008).

In architecture, similar approaches are applied as in urban planning. Rules are defined for the design and construction of new buildings and floor plans, such as the specification of rooms and their spatial relations. Stiny (1985) and Mitchell (1990) contributed to shape grammar rules in architecture.

In computer science, rule-based approaches were widely applied from the beginning. Related to urban design, software tools like CityEngine (ESRI 2012) or Synthicity (2013) considerably advance urban simulations and offer new possibilities in planning. Grammar rules can be directly implemented in computer codes. Some fields have overlapping aspects, such as the street network design often referred to in transport and urban planning.

Shape grammars are applied to simulate urban growth (Vanegas et al. 2009a; Weber et al. 2009), urban redesign (Bramley and Power 2009; Yerra and Levinson 2005), and changes on the demand side (Dutton 2000) - or even to visualize the potential of future technologies (Geddes 1939; Vanegas et al. 2009b). A comprehensive list of shape grammar rules and additional examples are provided in Section 3.

A grammar-based approach offers many advantages. Compared to other design methods, grammar rules are not only valid at a particular site or study area, but they can also be applied at many different planning sites. They can also be applied by network designers and spatial planners without extensive computational requirements. Grammars have the potential to overcome the complexity of transport network design. Rules can be transformed into future norms and design guidelines. They can be bequeathed to future generations and retain an urban vision for a longer time, such as for long-term strategic master planning of cities and urban regions. In addition, the potential of shape grammars can be exploited in a broader planning context. Established shape grammars in multiple fields enable synergies and will nurture future interdisciplinary planning applications. Fields such as transportation are linked to urban design and planning, architecture, and energy supply. Shape grammars might be able to overcome the vast complexity of this interdisciplinary topic.

Certain disadvantages evolve when applying grammars. Often, the future effects of the grammar after implementation are not known. However, planners need to know the effect of the grammar rules so they can create a meaningful design and follow the planning objectives. Here, it is stated that the effect of a proposed rule regarding an objective is needed for meaningful rule application. Objectives can be economic, sustainability, or societal measures.

This paper aims at contributing to a more meaningful application of grammars related to certain objective functions to overcome the drawbacks stated above. Shape grammars contribute to transport network and urban design, especially if they are established on a solid and quantitative evaluation. It is 
stated that quantitative evaluations of grammars regarding an objective shed more light on the effect of various network designs and uncover potential improvements and meaningful applications.

The structure of this paper is threefold. First, the understanding of shape grammars is enhanced by the presentation of detailed terminology, examples from different fields, and the consolidation and description of a general definition of grammars. The paper then explores how the theory of grammars for network and spatial planning should be congruent with the basic concepts of grammars in cognate fields to combine rules of multiple disciplines such as architecture and urban and transport planning (Section 2).

Second, the paper provides a general overview of the current state of shape grammar development. It does not claim to provide a complete literature review, but it does offer an overview and key achievements in the most relevant fields (Section 3).

Third, a systematic methodology is proposed for future shape grammar definition and assessments in transport and urban planning. A systematic methodology enhances cross-disciplinary research, synergies, and applications (Section 6). The methodology consolidates various achievements in the field of shape grammars. An example of a boulevard design is then useed to illustrate the proposed method$\operatorname{ology}($ Section 7).

\section{Terminology}

This section briefly defines the most relevant grammar-related expressions. The reader is referred to the wider literature of linguistics, grammars, and cognate fields for further details about the relevant terminology.

\subsection{Topology and morphology}

The American Planning Association (2006) defines urban morphology as the "study of the city as human habitat. Urban morphologists analyze a city's evolution from its formative years to its subsequent transformations, identifying and dissecting its various components. The city is the accumulation and integration of many individual and small group actions governed by cultural traditions and shaped by social and economic forces over time. Urban morphologists study the outcomes of ideas and intention as they take shape on the ground and mold cities. Buildings, gardens, streets, parks, and monuments are among the main elements of morphological analysis (American Planning Association 2006, p.401).”

Topology focuses on the network graph and studies shapes and their properties. Topology refers to non-metric information such as connectivity, orientation, adjacency, and containment or proximity, separation, succession, continuity, and closure (Marshall 2005, p.103).

\subsection{Patterns}

The meaning of pattern is twofold. Patterns may be designed or they may be emergent. In the first case, patterns often refer to a particular geometric layout, as a scale plan, featuring absolute position and lengths. Patterns can describe an extracted spatial form which is made of a number of elementary building blocks. A pattern can be used as an archetype for future planning.

Example patterns are layouts often used in design handbooks (e.g., AASHTO 2004; FGSV 2008; VSS 1994). Lynch (2001) mentioned star, grid, axial, nested, and other kinds of patterns, similar to Marshall (2005). Network patterns are assessed and compared in science (e.g., Estrada et al. 2011; Snellen et al. 2002; Xie and Levinson 2007).

Emergent patterns can be used as algorithmic structures to generate urban designs (Alexander et al. 1977), which is in contrast to the above definition.

In a bottom-up approach, no preconceived pattern exists; urban patterns unfold incrementally (Marshall 2005), and the result is an assembly of urban elements. Alexander et al. (1977) described the 
unfolding process in their seminal book A Pattern Language. This can lead to some misunderstanding, especially when compared to the archetype patterns described above.

\subsection{Syntax}

Syntax consists of the rules governing distinct elements, such as words in linguistics or elementary building blocks in urban planning. The expression is widely used in computer science to describe the combination of elements to build up a structured source code. Also, architects and urban planners often refer to syntax and assemble urban elements according to distinct rules.

The following definition extracts the major components of an early definition (Chomsky 1956, 1959).

The syntax $\mathscr{R}$ describes, in the form of a finite number of rules how elements $e$ of the same or different type are added to each other. $\mathscr{I}$ defines the initial assertion where the algorithm starts. $\mathscr{E}$ is the finite set of non-terminal elements $e . \mathscr{R}$ is a set of rules $r$ in the form of $\alpha \rightarrow \beta$, where $(\alpha, \beta) \in$ $\mathscr{E} . \mathscr{R}$ includes rules to stop the algorithm after initialization. The result is the infinite set of urban transport systems.

The rules describe how given planning states and urban geometries are extended to another state. Normally, $\alpha \neq \beta$ is valid, which means that an element $e$ cannot be transformed in itself to build up an urban system. Additionally, $\alpha \rightarrow\left\{\beta_{1}, \beta_{2}\right\}$, and $\left\{\alpha_{1}, \alpha_{2}\right\} \rightarrow \beta$ are valid because network design shape grammars are nonreversible.

The stopping criteria is often related to budget or space constraints in planning applications.

As an example, Table 1 proposes a context-free syntax $\mathscr{R}$ with corresponding elements $\mathscr{E}$ for hierarchical design.

$\mathscr{R}$ ignores external specifications and is therefore called context-free (Friedman et al. 1992). The elements $e$ can further be subdivided for more details, to follow further rules, and to cover additional fields in urban planning (besides transportation). Figure 1 displays another example of a hierarchical design, which is similar to $\mathscr{R}$ in Table 1 but extended with specific intersection types.

Marshall (2005) explained the rather "mechanistic" character of these rules. Many advantages occur when a rule-based approach is used. Rules allow flexibility and a diversity of outcomes. The application of rules allows for more adaptive networks, such as for variable urban densities of terrain, than rigid and standardized patterns such as gridirons.

\subsection{Shape grammars}

The following sections aim at a theoretical justification of grammars and their theoretical feasibility for planning purposes with corresponding semantics. As in computer science, rules can generate outcomes that are meaningless. Therefore, it is claimed that syntax alone is insufficient to generate a reasonable outcome, such as for an urban planning environment.

In this section, a general definition of shape grammars is proposed for urban and transport planning, contextualized and justified based on the current literature about grammars in cognate fields. We also look at the properties of grammars and seek to define them as encompassing and ultimately necessary for planning applications.

Multiple distinct definitions of grammars exist in linguistics. The distinct definitions approach syntax, language, and semantics in different ways. Scanning recent literature about grammars discloses an ongoing debate even in linguistics, which complicates the transferability of findings to transport and urban applications.

It is assumed in the following that shape grammars are applied in an urban and transport planning context. Moreover, it is assumed that planners act rationally and follow a certain overall intention, such as a sustainability goal or cost minimization, which is explicitly defined or implicitly followed. 
Table 1: Example context-free syntax $\mathscr{R}$ for hierarchical network design with a corresponding set $\mathscr{E}$ of defined, generic road and intersection elements $e$.

\begin{tabular}{|c|c|}
\hline Formal rule & Description \\
\hline \multicolumn{2}{|l|}{ Vocabulary $\mathscr{E}=\left\{e_{1}, e_{2}, e_{3}, \ldots\right\}$} \\
\hline$e_{1}$ & Arterial road \\
\hline$e_{2}$ & Access road \\
\hline$e_{3}$ & Local road \\
\hline$e_{4}$ & Right-of-way junctions \\
\hline$\rightarrow$ & The left side of " $\rightarrow$ " is transformed to the right side of " $\rightarrow$ ". \\
\hline+ & The left side of " + " is adjacent to the right side of " $+"$. \\
\hline \multicolumn{2}{|c|}{ Context-free syntax $\mathscr{R}=\left\{r_{1}, r_{2}, r_{3}, \ldots\right\}$} \\
\hline$r_{1}: e_{1} \rightarrow e_{1}+e_{1}$ & $\begin{array}{r}\text { Network connectivity requires arterial roads to connect to } \\
\text { other arterial roads. }\end{array}$ \\
\hline$r_{2}: e_{1}+e_{1} \rightarrow e_{1}+e_{1}+e_{2}$ & $\begin{array}{l}\text { Arterials can be joined with an access road if a connected } \\
\text { arterial network is maintained. }\end{array}$ \\
\hline$r_{3}: e_{2}+e_{3} \rightarrow e_{2}+e_{3}+e_{4}$ & $\begin{array}{r}\text { An access road connected to a local road requires a } \\
\text { right-of-way junction. }\end{array}$ \\
\hline
\end{tabular}

$r_{4}: \ldots$

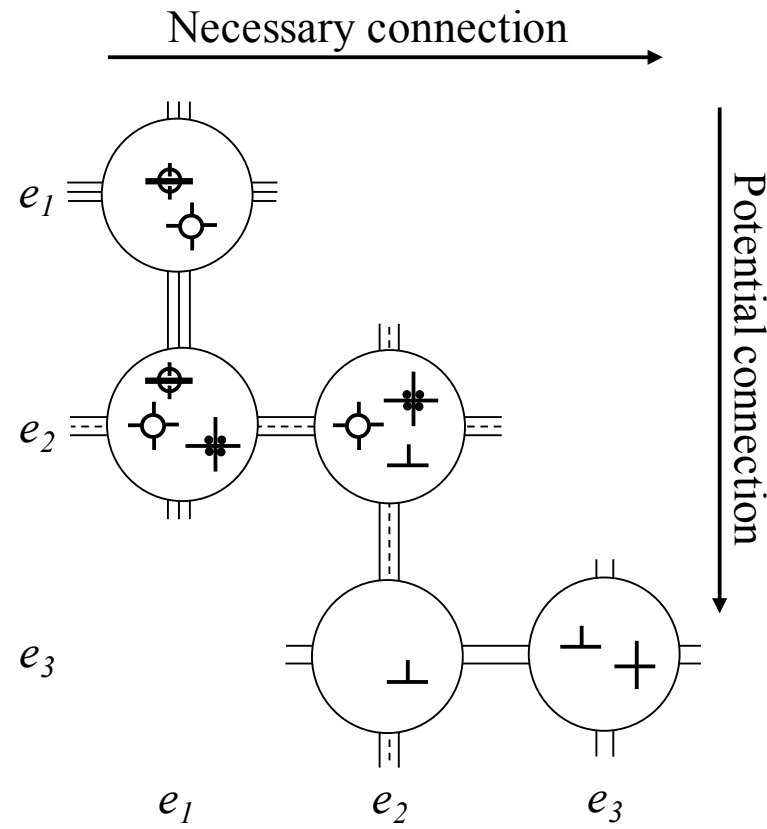

Network elements $\mathcal{E}$ :

$\overline{\overline{\overline{2}}} e_{1}$ : Minor Arterial

$\overline{-\cdots \cdots} e_{2}$ : Access Road

$=e_{3}$ : Local Road

$+e_{4}:$ Crossing

$\perp e_{5}:$ T-junction

$\stackrel{\oplus}{\oplus} e_{6}$ : Light-signal system

- $e_{7}:$ Roundabout

† $e_{8}$ : Multiple level node

Figure 1: Example of rules for a hierarchical road network design (Marshall 2005). 


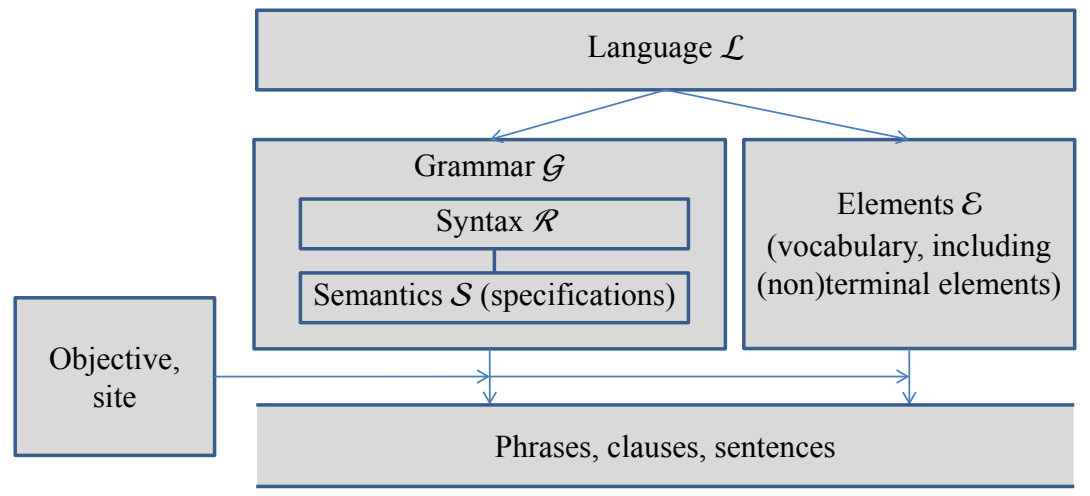

Figure 2: Contextualized language setup for shape grammars with exogenous planner's objective.

The expression "objective" is deployed to define the intention in a qualitative or quantitative manner. Additionally, it is supposed that planners act in a spatially defined area, called a "site," which they intend to change directly or indirectly through structural changes.

Figure 2 summarizes and embeds the grammar context. It is shown that grammars consist of syntactic rules and corresponding semantics. As in computer science, rules without semantics can generate outcomes that are meaningless. Therefore, it is claimed thatsyntax alone as it is defined in Section 2.3 is insufficient to generate a reasonable outcome and meaningful design in an urban planning environment.

It might be obvious that a rule is limited to a certain purpose or meaning. Certain rules are designated for a specific context; for example, housing construction in the tropics requires different rules than construction in moderate climates.

Application specifications can describe the required environment to apply the rules. The environment can include adjacent infrastructure or global components such as weather, social parameters, etc. Or, certain rules might be defined for urban environments while others are defined for rural environments. Therefore, it is claimed that, besides syntax, grammars include application specifications.

Application specifications are valid for one specific rule and therefore contrast the "site" definition above, referring to the planner's view. The inclusion of application specifications differs from the definition of context-free grammars (Chomsky 1956, 1959). Applying the same rule with different application specifications might lead to a different outcome. Specifications are equivalent to semantics in linguistics. Therefore, Figure 2 subdivides grammar $\mathscr{G}$ in syntax $\mathscr{R}$ as a rule set, and semantics $\mathscr{S}$ as corresponding application specifications. $\mathscr{R}$ is responsible for the "mechanics" of a certain language $\mathscr{L} . \mathscr{S}$ is basically responsible for all the information except the rules themselves. In particular, $\mathscr{S}$ contains information about the effect of $\mathscr{R}$, such as effects on efficiency, safety, etc. Moreover, $\mathscr{S}$ defines the application range in which $\mathscr{R}$ can be applied for reasonable design.

This specific subdivision of $\mathscr{G}$ in $\mathscr{R}$ and $\mathscr{S}$ also allows a more specific phrasing. Semantics are excluded when referring to rules. Rules and semantics are both addressed when referring to grammars. The application specifications obviously limit the application range of grammar rules. Reassessment, discretion, and expert knowledge might adapt existing rules and application specifications.

The lower two elements in Figure 2 refer to the general application of shape grammars, and therefore include the planner's objective, site, and resulting urban design. Obviously, the phrases, clauses, or sentences represent buildings, neighborhoods, or transport networks in the case of urban shape grammar applications.

Supplementing the definition of shape grammars, "shape" can be defined in a rather technical way. From a geometric perspective (Lord and Wilson 1984), shape includes a set of marks with position and orientation. Here "shape" refers to the urban and network design context. Stiny and Mitchell (1980) or Beirão (2012) also defined shapes from a strongly geometric perspective. 


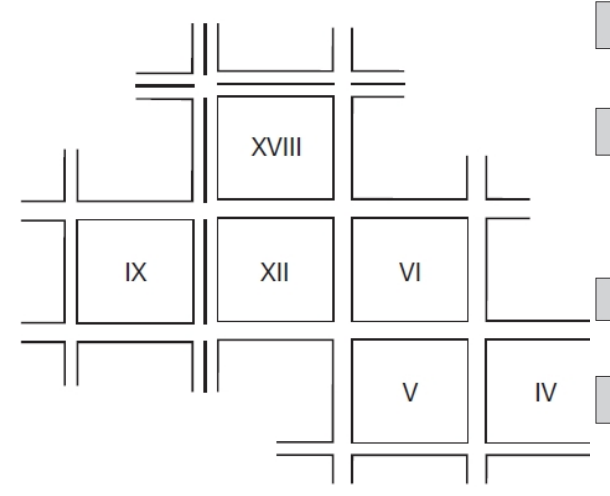

(a) Adjacent block types.
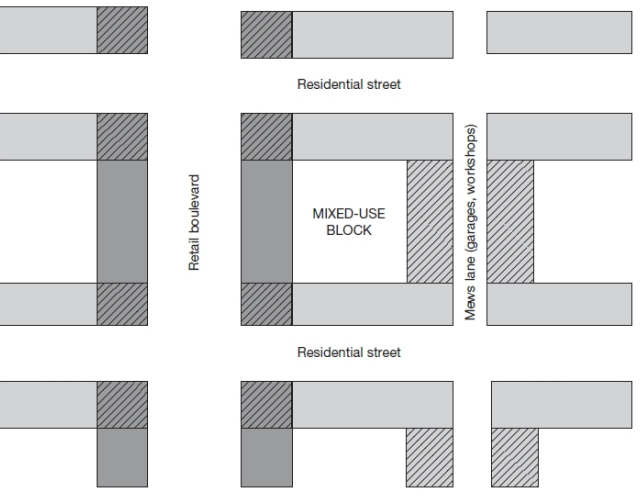

(b) Mixed adjacent block types.

Figure 3: Hierarchical road network design and adjacent block types (Marshall 2005, p.240, 241).

"Shape" is slightly ambiguous in the context of transport networks since grammars apply not only to physical shapes, but also to certain functionalities like speed limits at road types and priority rules at intersections. Still, "shape" is widely used in the urban planning context. Therefore, the term "shape grammars" is used in the following section, but the expression also includes shapes in the wider sense, including items like capacities and speeds.

The provided shape grammar example refers to road type distribution within a given network topology. The syntax of a hierarchical network design was described in Section 2.3 and in Figure 1. Application specifications are further required for more meaningful designs. In the example of Figure 2.5, Marshall (2005) additionally defined land-use types adjacent to the road types. These specifications state that grammar rules need to be embedded in a denser urban area, and, moreover, they should match the land-use types adjacent to the roads for meaningful design. Figure 3(a) shows the assignment of six block types and the interplay with adjacent street types. Figure 3(b) allows even mixed use within the same block. Both examples show that the rules stated above are not stand-alone rules; they are embedded in a set of additional specifications, which have to be considered in planning.

\subsection{Similarities and differences in existing approaches}

Beirão (2012) also referred to shape grammars and semantics. He highlighted the missing interpreter, which is similar to the missing semantics stated above and to Fleisher (1992), who also recognized the failure of the missing linkage between grammar rules and semantics. Moreover, Beirão (2012) stated that literature exists about rules, but the rules are difficult to apply due to a lack of meaning and interpretation. The stated matching problem refers to the difficulties of applying grammars in the right way.

Beirão (2012) mentioned that grammars of natural languages are already accepted agreements and a premise in applications. This leads to a consistency problem when designing, because in this case the grammar is not a premise but a product of the design process. Therefore, on one side, it is argued that grammars exist already in natural and eventually design languages. Then, grammars can be extracted and determined analytically from the environment as case studies and can be further pursued in future applications. On the other side, it can be also stated that grammars have evolved over time and are the results of the needs and requirements of the language users. At this point, the analytical approach of extracting grammars and the applied approach of this paper fork in their methodologies. Whereas the analytical approach (Figure 4(a)) extracts grammars from the environment by reverse engineering (Courtat et al. (2011) and the empirical evaluation of link lengths and angles), the approach presented in this paper defines grammars based on fundamental knowledge of the functioning of a design issuein this case, transport networks. If certain features or characteristics, such as a specific intersection type 


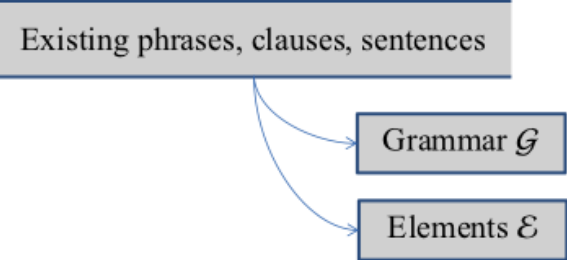

(a) Analytical approach

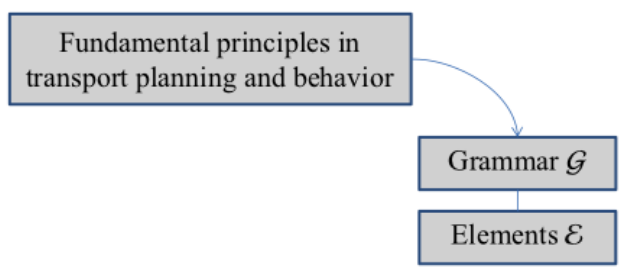

(b) Inductive approach

Figure 4: Schematic differences between the analytical and inductive approach for shape grammar definition.

or road spacing, are known to be more efficient in certain cases, this knowledge should be formulated and stated within an appropriate rule. Therefore, we can define rules based on fundamental principles of design, well-known characteristics, and even physical laws. Moreover, existing design handbooks can rely on these findings. This approach is called an inductive approach (Figure 4(b)) and is elaborated throughout this paper.

Differences between the analytical and inductive approach can be observed in existing literaturefor example, between the approaches of Stiny and Mitchell (1980) or Beirão (2012), which focus especially on geometry and are at least partially based on case studies, and the approaches of Alexander et al. (1977) or van Nes (2003), which describe grammars in a more descriptive manner based on safety considerations and define grammars based on economic optimization in the case of transit stop spacing.

Similar to Alexander et al. (1977), most of the proposed shape grammars are formulated and defined in a descriptive manner and therefore contrast the definition of rules based on exact shapes and their potential connection, as defined in Stiny (1985). Reasons for a descriptive formulation of shape grammars might be the complexity of urban networks. It is stated that some of the generated grammars cannot be defined in an abstract manner or as geometric output. For example, city design might be a combination of a gridiron and signals, but depending on the purpose and the major modes using the gridiron, it has a different spacing and is combined with different intersection types. Summing up, not all rules can be defined as the transformation of exact shapes; some rules have to be defined in a more descriptive manner. An additional remark is provided when describing the final grammars (Section 7.6).

\section{Existing grammars}

\subsection{Cognate fields applying grammars}

Table 2 lists selected cognate disciplines applying grammars, referring firstly to the field of linguistics and computer science as early milestones in grammar evolution. The subsequent achievements evolved in parallel or consecutively and are described below.

Grammars are systematically applied in linguistics. Chomsky $(1956,1959)$ has been one of the first contributors to formal grammars. A formal language is defined as a language $\mathscr{L}$, independent of its field or origin, of an infinite set. However, the language and structure of $\mathscr{L}$ can be investigated through the study of finite devices: the grammars $\mathscr{G}$, which are capable of enumerating its sentences (Stiny and Gips 1972). Based on this linguistic definition, the shape grammar language $\mathscr{L}(\mathscr{G})$ has been modified, specified, and transferred to many other fields. 
Mathematics, and particularly logic, employed grammars at an early stage. Logic defines an alphabet that consists of terms, symbols, and variables. Formulations follow defined rules. For example, "=" is defined as standard equality; both sides of the formulation are equal. Sentences can be generated following the rules and above alphabet.

At this point, it is interesting to note that Fagin (1974) subdivided all sentences of logic, especially complex problem formulations, into two distinct classes: $\mathscr{P}$ (solvable in polynomial time) and $\mathscr{N} \mathscr{P}$ (non-deterministic polynomial-time hard). This classification subdivides sentences according to their complexity (Garey and Johnson 1979; Zimmermann 2008). If $n$ is the problem size and $\mathscr{O}(f(n))$ the calculation costs, $f(n)$ is a polynomial function for all problems in $\mathscr{P}$. Problems in network design are often $\mathscr{N} \mathscr{P}$ (Johnson et al. 1978) and solvable only in exponential time. This affects transport and spatial planning considerably and leads to long calculation times in its optimization algorithms. Therefore, heuristics have become more interesting in recent years to solve complex problem formulations.

Operations research, and especially artificial intelligence, profit from optimization rules to solve complex problems, especially in (meta-)heuristics. An example is given by Goldberg (2002). The wellknown building blocks are defined clusters in a genetic code, similar to genes in a genome. Instead of recombining single elements of the genome, clusters of multiple and efficient elements are recombined to futher improve efficiency. Coates (2010) takes up this idea and defines buildings as clusters. Both examples show rule-based methods in the field of operations research.

Computer science implements precisely defined syntactic structures for various applications. One has to emphasize that syntax alone is insufficient for a working code. Interpreters are required to perform the actions indicated in the code. Errors such as null-pointer exceptions can still occur, even with a syntactically correct code. A working code does not necessarily fulfill the requirements of the user and is not meaningful per se. For example, cellular automata (Wolfram 2002) describe rules to continue from a starting or intermediate state to a consecutive state; however, they might not pursue an overarching goal. Therefore, standalone rules are inefficient without a detailed description of the application specifications. This also holds for planning, which will be shown later in this chapter.

In geometry, Stiny and Gips (1972) and Stiny and Mitchell $(1978,1980)$ remain influential. The geometry-based languages can be used for geometric art objects such as paintings or sculptures. The application fields range from geometric paintings, procedural modeling, and evolutionary and growth processes to conceptual design and aesthetic and visual arts.

Besides many other geometric applications, Prusinkiewicz and Lindenmayer (1996) proposed the L-System, which consists of grammar rules and an alphabet of symbols, making larger and more complex systems such as plant morphologies possible through recursion.

Various authors have contributed to grammars in architecture, urban planning, and transportation at the same time due to overlapping design aspects. The most relevant examples are mentioned below.

In architecture, the seminal contribution of Alexander et al. (1977) applied grammar principles to the languages of architecture and urban planning. The pattern language of Alexander et al. (1977) consists of a vocabulary including settlements, buildings, and elements of the buildings; therefore, it varies in scale and covers architecture and urban and transport planning. The grammars describe which elements of the vocabulary and their combinations are more desirable and which combinations are inadvisable.

March (1976) assign geometric design of buildings to an elementary boolean code, including elements and operations.

The methods of Stiny and Gips (1972) and Stiny and Mitchell (1980) are also adapted to design and construction purposes. For example, the prairie houses of of Frank Lloyd Wright were evaluated regarding their grammar (Koning and Eizenberg 1981; Stiny 1985). Recently, grammars have increasingly been used in the visualization of buildings and in the film industry (Parish and Müller 2001; Vanegas et al. 2010), which also relates to computer science. 
In urban planning, Sorkin (1993) and Cowan (2002) developed guidelines and prescriptions for general urban development in a qualitative way. Their work can be related to the movement of New Urbanism (Dutton 2000; Haas 2008; Mehaffy 2008). Following up on the idea of New Urbanism, a new set of codes were developed for urban design.

In a very early stage, Stübben (1907) contributed to a formal definition of street segments and their relations. Smart Code (Duany et al. 2009) is a well-known rule set, incorporating all scales of urban planning, and is applied in multiple neighborhoods in the U.S. and worldwide.

Sustainable Street Network Principles (CNU 2012) were developed for transportation reform and contributes to the field of New Urbanism. The focus is on walking and improved pedestrian infrastructure and other modes of transport.

A growing number of software solutions apply shape grammars for urban simulations (e.g., ESRI 2012; UrbanVision 2012).

In transportation, multiple norms and guidelines propose network design recommendations (AASHTO 2004; FGSV 2008; IHT 1997; VSS 1994) such as hierarchical road layout implicitly or explicitly stated as rules. However, already in an early stage, LeCorbusier (1955) applied a strong hierarchical approach to city planning, similar to a rule-based approach. He suggested a hierarchical approach for road network design. The idea of a hierarchical approach is implemented in the different standards of western countries. Alexander et al. (1977) contributed to road network layouts. Marshall (2005) introduced shape grammars by defining relationships between network element types without presupposing any particular final form. Van Nes (2003) and Yerra and Levinson (2005) followed up on the hierarchical network layout and specified spacing, hierarchies, economic impacts, and additional aspects.

\subsection{Advantages and disadvantages}

Various applications of rule-based approaches could be found in literature, even if they are not stated explicitly as rule-based methods. Regarding the application of shape grammars, key advantages are consolidated and listed below.

- Shape grammars provide straightforward application tools for planning processes (Jacobi et al. 2009; Parish and Müller 2001; Watson et al. 2008). Planners prefer robust and reliable methods to fulfill economic and social requirements. Shape grammars can satisfy these requirements and still remain adaptive to different scenarios (Jacobi et al. 2009; Marshall 2005; Weber et al. 2009).

- Shape grammars can be applied on different planning sites, as opposed to a bi-level optimization algorithm and its results, which are only valid for a specific site and case study area.

- Grammars retain in space and time. They are applicable to different planning sites. A rule set allows an urban vision to be retained for a longer time (Alexander et al. 1977; LeCorbusier 1955) and for long-term strategic master planning. Planning authorities might change over years, but detailed grammar descriptions enable planning rules to be passed on to future generations. Rules can be applied in a piecemeal approach, which allows certain flexibility over time.

- Urban economics, transportation, and energy supply form complex decentralized systems (Lämmer et al. 2006). Knowledge about efficient leverage effects are essential for a successful design. Moreover, bottom-up rules are often accepted regulation methods.

- Shape grammars originating from various disciplines can be joined together for an even larger set of grammars for interdisciplinary applications (Alexander et al. 1977; Haas 2008). The multidisciplinary potential contrasts the distinct languages of specific disciplines. The distinct languages are often too sophisticated to interact with each other. The distinct disciplines often deploy methods and models, which cannot be merged with methods of other, even cognate disciplines. Shape grammars overcome this interdisciplinary complexity with their straightfor- 


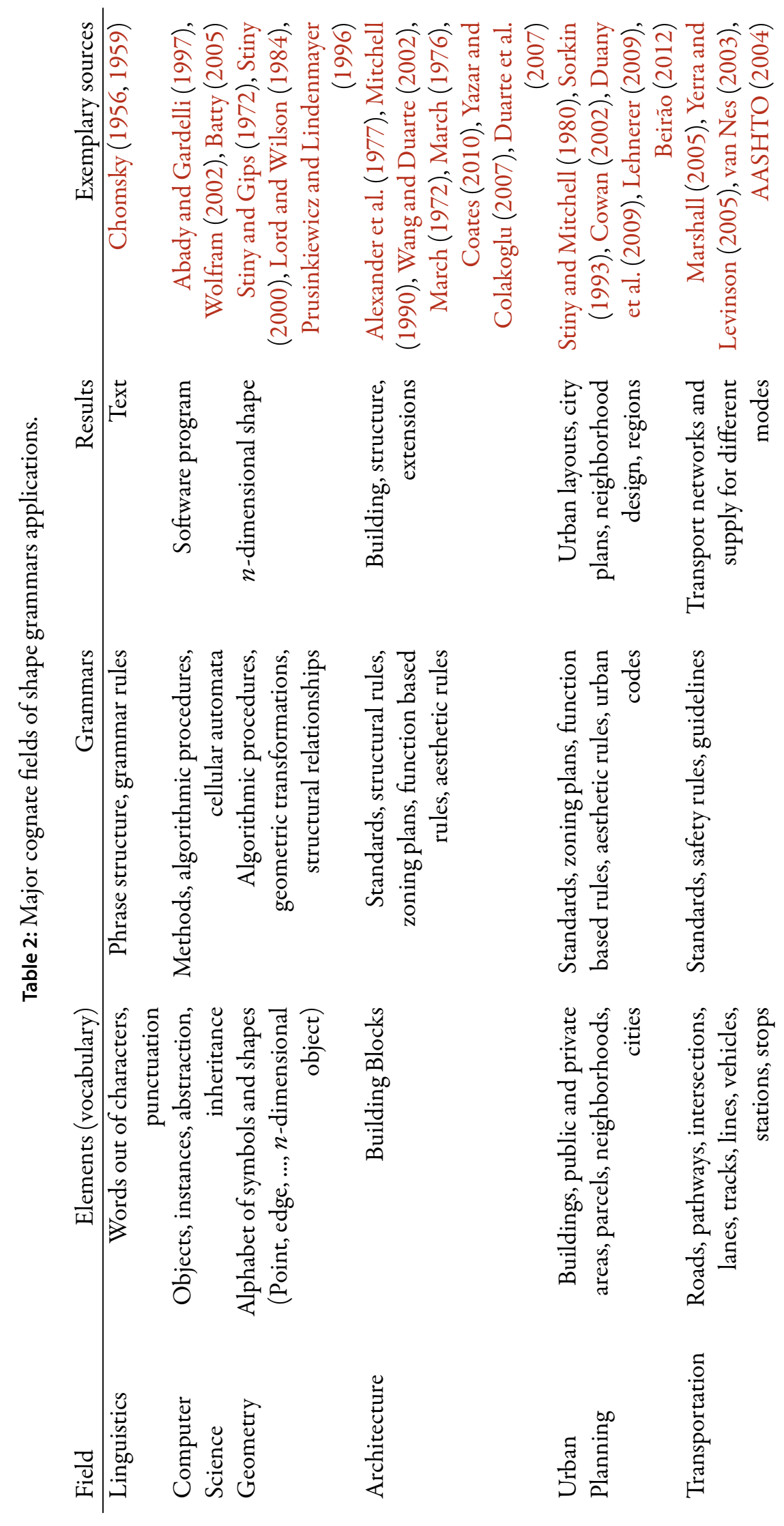


ward definitions. The multidisciplinary rules can enable the accomplishment of encompassing tasks, such as energy demand and supply (Keirstead and Shah 2011).

- The application of shape grammars permits low computational costs (Parish and Müller 2001; Watson et al. 2008) and can be implemented in interactive planning tools (Jacobi et al. 2009; Weber et al. 2009) given limited staffing resources. Therefore, grammars are in contrast with spatial optimization, such as bi-level network optimization, regarding computational requirements.

- Deeper understanding of the structure of urban systems enhances overall urban planning and the understanding of urban guidelines (Hillier et al. 1976; Michie 1974). Beirão (2012) stated that certain solutions might appear during the course of exploration of a certain problem. So grammars can be transformed to urban guidelines for future planning applications. This contrasts with complex "blackbox" and cumbersome mathematical optimizations and the corresponding results, which are restricted to a specific site.

- Shape grammars are applied to simulate urban growth (Vanegas et al. 2009a; Weber et al. 2009), urban redesign (Bramley and Power 2009; Yerra and Levinson 2005), changes on the demand side (Dutton 2000), or even at new technologies (Geddes 1939).

Disadvantages of shape grammars could be found as well and are stated below:

- The effectiveness of shape grammar rules is often unknown in urban planning applications. Especially the assessment challenges the definition and application of grammars. The assessment requires a deeper understanding in the corresponding fundamental urban processes. For example, network design rules often lack a systematic evaluation, such as cost-benefit analyses, and do not remain explicit in their recommendations.

- The vast majority of research results are not formulated in shape grammar notation. We lack shape grammar formulations, despite broad expertise in the distinct planning disciplines. However, a potential transformation of the existing expertise and results into shape grammar rules would allow us to enlarge the rule sets considerably and simultaneously exploit the enormous potential for various grammars applications.

- Grammar rules might need adaption due to changing environments, because rules might become impractical in the future due to technological and behavioral changes.

- Rules are often based on a long-lasting expert knowledge and experience, common understanding, human perception, and aesthetic preferences. The validation especially of subjective rules might be ambiguous.

\section{Classification}

\subsection{Taxonomy}

This section narrows down the broad view of Section 3 to urban and transport planning and provides a systematic overview of the existing set of shape grammar rules.

Existing shape grammar classifications for urban planning and transportation can be found in Alexander et al. (1977) and Marshall (2005). Drawing on the broader existing literature, shape grammars can be assigned to divisions and classes, summarized in Table 3 for transport networks and Table 4 for urban planning.

Various classifications are possible for shape grammar taxonomy. A function-based classification is proposed to address the purpose of each grammar. The divisions include geometry, composition, and investments and regulations; these divisions subdivide the entire shape grammar set for both urban and transport planning. More detailed classes, compared to the divisions, describe the aim of the rule more specifically. Table 3 and Table 4 serve as an overview of existing shape grammar rules. They can be extended with more examples and additional classes. 
A list of urban elements is required for completion of the language definition (Figure ??). However, we skip detailed descriptions and classifications of the elements of the urban shape grammar language due to lack of space. Various sources exist for network elements, such as Alexander et al. (1977).

As an example, a potential classification in urban planning might include roads, tracks, blocks, zones, landscapes, and focal points as elements of an urban design language (Lynch 1960).

Table 3: Classification of transport planning grammars.

\begin{tabular}{|c|c|c|}
\hline \multicolumn{3}{|l|}{ Divison } \\
\hline Class & Description & Exemplary sources \\
\hline \multicolumn{3}{|l|}{ Geometry: } \\
\hline Angle & Angle of adjacent road types & Vanegas et al. (2009a) \\
\hline Loops & $\begin{array}{r}\text { Circuit or cell-based road and line } \\
\text { alignment, size of circuits }\end{array}$ & Levinson and Huang (2012) \\
\hline Numbers & $\begin{array}{l}\text { Number of arms for intersections, dead } \\
\text { ends, number of lanes for road types }\end{array}$ & $\begin{array}{r}\text { Alexander et al. (1977), Vanegas } \\
\text { et al. (2009a) }\end{array}$ \\
\hline $\begin{array}{l}\text { Curvature, } \\
\text { slope }\end{array}$ & Curvilinear design, steepness & Weber et al. (2009) \\
\hline \multicolumn{3}{|l|}{ Composition: } \\
\hline Connectivity & $\begin{array}{r}\text { Connected elements, e.g., connected } \\
\text { freeway or high speed rail }\end{array}$ & AASHTO (2004) \\
\hline Function & $\begin{array}{l}\text { Adjacent land use and building types, } \\
\text { road access, parking, toll cordon }\end{array}$ & Marshall (2005), Dutton (2000) \\
\hline Hierarchy & $\begin{array}{r}\text { Hierarchical road and intersection type } \\
\text { distribution, Hierarchical service type } \\
\text { distribution, stop densities, service } \\
\text { frequency }\end{array}$ & $\begin{array}{l}\text { Marshall (2005), Weber et al. } \\
\text { (2009), Gil and Read (2012), VSS } \\
\text { (1992), FGSV (2008), Marshall }\end{array}$ \\
\hline Variation & $\begin{array}{l}\text { Irregularity and variance in design (e.g., } \\
\text { in old town vs. in uniform grid) }\end{array}$ & Alexander et al. (1977) \\
\hline \multicolumn{3}{|c|}{ Investments and regulations: } \\
\hline Density & $\begin{array}{r}\text { Total road length, total number of } \\
\text { intersections, block size, parallel roads, } \\
\text { stop intervals }\end{array}$ & $\begin{array}{r}\text { Van Nes (2003), Levinson and } \\
\text { Huang (2012), Levinson et al. } \\
\text { (2012) }\end{array}$ \\
\hline System & Transport modes & $\begin{array}{r}\text { LeCorbusier (1955), Geddes } \\
\text { (1939), van Nes (2003) }\end{array}$ \\
\hline
\end{tabular}

\section{Applications}

An increasing number of software applications exist for shape grammars. This underlines the importance of shape grammars in urban and transport planning.

Beirão (2012) developed a set of tools for combining design patterns as part of the project City Induction (Duarte et al.2012). It allows for the composition of an urban solutions for neighborhoods relying on a rule-based approach.

Caneparo et al. (2007) describe a tool for building and neighborhood scenarios, incorporating rules in the design process as well as evaluations of the suitable candidate solutions.

CityEngine (ESRI 2012) and UrbanCanvas (Synthicity 2013) are commercial tools, and both rely on procedural $3 \mathrm{D}$ modeling. Whereas the first builds on GIS data, the latter uses transport and land-use models. Grammar-based 3D modeling is also applied interactively for participatory design of planners and stakeholders (Jacobi et al. 2009). 
Table 4: Classification of existing urban planning grammars.

\begin{tabular}{|c|c|c|}
\hline \multicolumn{3}{|l|}{ Division } \\
\hline Class & Description & Sources \\
\hline \multicolumn{3}{|l|}{ Geometry: } \\
\hline Building shape & Footprint, 3D shapes, angles & $\begin{array}{r}\text { Stiny (1985), Schirmer and } \\
\text { Kawagishi (2011) }\end{array}$ \\
\hline $\begin{array}{l}\text { Parcels, } \\
\text { neighborhoods }\end{array}$ & Assignment and design & Kaisersrot (2011), Lynch (1981) \\
\hline City design & $\begin{array}{r}\text { Assignment and design, land use, } \\
\text { prices }\end{array}$ & $\begin{array}{r}\text { Alexander et al. (1987), Lehnerer } \\
\text { (2009), Batty (2005), Duarte et al. } \\
\text { (2012), White et al. (2012), } \\
\text { Duarte et al. (2007) }\end{array}$ \\
\hline \multicolumn{3}{|l|}{ Constitution: } \\
\hline Function & Building and neighborhood type & $\begin{array}{r}\text { Kaisersrot (2011), Duany et al. } \\
\text { (2009), Dutton (2000) }\end{array}$ \\
\hline $\begin{array}{l}\text { Material, and } \\
\text { construction }\end{array}$ & & $\begin{array}{r}\text { LeCorbusier (1955), Stiny and } \\
\text { Mitchell (1980), Heisel and } \\
\text { Yitbarek (2013) }\end{array}$ \\
\hline \multicolumn{3}{|c|}{ Investments and regulations: } \\
\hline Density & $\begin{array}{r}\text { Units, population, building mass } \\
\text { and densities }\end{array}$ & $\begin{array}{r}\text { Bramley and Power (2009), } \\
\text { Geddes (1939), König and Müller } \\
\text { (2011), Duany et al. (2009) }\end{array}$ \\
\hline $\begin{array}{l}\text { Ownership and } \\
\text { social interaction }\end{array}$ & Public and private space & $\begin{array}{l}\text { Copper Marcus et al. (1998), } \\
\text { Lehnerer (2009), Dutton (2000), } \\
\text { Mikoleit and Puerckhauer (2011) }\end{array}$ \\
\hline
\end{tabular}

Architecture-related software tools can be found, for example, in Yazar and Colakoglu (2007).

\section{Shape grammar assessment}

Objectives of urban planning projects include one or multiple goals, possibly with an economic, social or environmental focus. The objective might be increasing the quality of urban life, ecology, the economy, or a compound measure. Planners apply explicit and implicit rules to reach the objectives.

It is claimed that knowledge about the outcome of shape grammars and their implementations enhance future applications and might even become a touchstone for reapplications.

Therefore, distinct grammar rules are assessed regarding specific objective functions. Literature provides a variety of assessment tools focussing on generalized costs, economics, or environmental indicators. Table 5 lists example objectives and assessments methods with references of explicitly or implicitly stated grammars. Preferably, the evaluation measure for a shape grammar rule is exchangeable due to different application purposes and to correspond with the scopes of the tasks of planners. Sensitivity analysis (Kleijnen 2008; Saltelli et al. 2008) can be applied at all methods and complement Table 5. Some of the assessment methods might focus more on the analytical approach, such as the empirical evaluation (Section 2.5).

Table 6 describes example shape grammar rules with corresponding effectiveness measures. The rules might be not stated as such, but the results can be formulated as rules. Moreover, the application specifications describe the potential area of application.

Three examples of grammar rules, effectiveness measures, and application specifications are provided in Table 6. 
Table 5: Potential assessment methods and effectiveness measures for shape grammars.

\begin{tabular}{|c|c|c|}
\hline Evaluation method & Effectiveness measure & Example sources \\
\hline Cost-benefit analysis & $\begin{array}{l}\text { Generalized costs, external } \\
\text { effects }\end{array}$ & $\begin{array}{r}\text { Van Nes (2003), Estrada et al. } \\
\text { (2011), VSS (2006c) }\end{array}$ \\
\hline Sustainability measures & Sustainability & $\begin{array}{r}\text { Gil and Read (2012), Duarte et al. } \\
\text { (2012), NISTRA (Lieb et al. } \\
\text { 2003), HEATCO (University of } \\
\text { Stuttgart 2014) }\end{array}$ \\
\hline Empirical evaluation & $\begin{array}{l}\text { Modeling historical } \\
\text { development }\end{array}$ & $\begin{array}{r}\text { Strano et al. (2012), Levinson et al. } \\
\text { (2012), Stiny and Mitchell (1980), } \\
\text { Strano et al. (2012) }\end{array}$ \\
\hline Qualitative analyses & variable & $\begin{array}{r}\text { Marshall (2005), Alexander et al. } \\
\text { (1977) }\end{array}$ \\
\hline Surveys & Behavior, acceptance & Bramley and Power (2009) \\
\hline
\end{tabular}

Table 6: Three examples of objectives, implicitly or explicitly stated grammar rules, effectiveness measures, and application specifications.

\begin{tabular}{lrrr} 
Purpose & Grammar rules $\mathscr{R}$ & $\begin{array}{r}\text { Effectiveness } \\
\text { measure }\end{array}$ & $\begin{array}{r}\text { Application } \\
\text { specifications }\end{array}$ \\
\hline $\begin{array}{l}\text { Private transport and } \\
\text { transit network } \\
\text { characteristics (van }\end{array}$ & $\begin{array}{r}\text { Road spacing and } \\
\text { hierarchies, transit } \\
\text { nes 2003) }\end{array}$ & $\begin{array}{r}\text { User costs and } \\
\text { network }\end{array}$ & $\begin{array}{r}\text { Model application } \\
\text { infrastructure costs }\end{array}$ \\
$\begin{array}{l}\text { characteristics lanes, headways, } \\
\text { rocial sustainable }\end{array}$ & Urban density \\
living (Bramley and & Social sustainability & $\begin{array}{r}\text { Survey of English } \\
\text { Power 2009) }\end{array}$ \\
planning & & & $\begin{array}{r}\text { Housing, Census of } \\
\text { Population (England } \\
\text { and Wales) }\end{array}$ \\
$\begin{array}{l}\text { Transport network } \\
\text { design (Yerra and }\end{array}$ & Hierarchical street \\
Levinson 2005) & Link-based revenue & $\begin{array}{r}\text { Road infrastructure } \\
\text { investment, model }\end{array}$ \\
& & & application
\end{tabular}

\subsection{Enhanced choice set generation}

Planners aiming at defining subsets of rules that are more appropriate in certain planning sites compared to other subsets of different rules. The defined application specifications of grammar rules are able to narrow the set of rules down to a well-defined subset. It is aimed at deriving an optimized set of the most relevant grammar rules to support planners' objectives.

It is proposed to subdivide the effectiveness measure in two parts: the direction of the transformation, and the degree of transformation.

- The direction describes the transformations of the system related to an effectiveness measure. There might be a negative, positive, or no effect regarding the objective.

- The degree describes the changes of the system regarding the actual effectiveness measure. There might be a significant change within the system when it is in an elastic state. There also might be a minor change in an inelastic (stable) system regarding the given objective.

This research proposes marginal effectiveness and elasticities $\epsilon$ for the further measurement of the effectiveness measure. Elasticities are robust and accepted measures for assessing the response of an observed variable. Marginal changes and accessibility assess the variations of an outcome of an objec- 
tive function related to the changes of an independent variable. In the current case, dependent variable $O$ equals the user costs, and the independent variable equals an underlying investment $I$ change: $\left(\frac{\delta O}{\delta I}\right)$. In the context of shape grammars, marginal costs describe the efficiency of a specific rule with regards to a given effectiveness measure.

Elasticities are free of units $\left(\epsilon=\frac{\delta O}{\delta I} \frac{\bar{I}}{\bar{O}}\right.$, when assuming linearity), facilitating comparison between different studies (Ewing and Cervero 2010). Recent achievements in survey methodology have enhanced elasticity estimations, aiming at more sophisticated urban and transport modeling (Goodwin et al. 2004; Hackney et al. 2007; Sanni and Albrantes 2013; Weis and Axhausen 2009).

Table 7 provides three examples of elasticity calculations in urban and transport planning.

Table 7: Three examples of elasticities in urban and transport network design.

\begin{tabular}{lrrr} 
Scope of grammar & $\begin{array}{r}\text { Efficiency } \\
\text { measure }\end{array}$ & Independent variables & Source \\
\hline Hierarchical network & VMT & $\begin{array}{r}\text { Intersection and street } \\
\text { densities }\end{array}$ & $\begin{array}{r}\text { Ewing and Cervero } \\
(2010)\end{array}$ \\
$\begin{array}{l}\text { Properties of planar } \\
\text { graphs }\end{array}$ & Efficiency & $\begin{array}{r}\text { Relative costs } \\
\text { (densities) }\end{array}$ & $\begin{array}{r}\text { Cardillo et al. } \\
\text { Road network } \\
\text { investment (expansion) }\end{array}$ \\
Accessibility, & $\begin{array}{r}\text { Speed, capacity, } \\
\text { travel demand }\end{array}$ & Weis (2012) \\
infrastructure cost
\end{tabular}

Potential applications of elasticities are related to energy consumption, emissions, generalized travel costs, quality of urban space, and satisfaction of residents (Bramley and Power 2009). The determination of the elasticities requires systematic data collection and processing.

A major drawback of many elasticities evaluations relates to the assumed underlying linear function involved and the calculation of the average utility (Train 1986). Elasticities are calculated for mean values. Single values can be under- and overestimated. For example, in value of travel time estimations, the linear model is outperformed by a more detailed nonlinear function (Hess et al. 2008). Section 7.4 proposes an approach to overcoming some aspects of this issue.

Elasticity calculation also includes sensitivity analyses. Sensitivity analyses uncover technical errors, find critical input variables, and determine model quality. Sensitivity analyses quantify and analyze uncertainty propagation and bring into relationship the uncertainty of the output to different sources of uncertainty in the model input (Kleijnen 2008; Saltelli et al. 2008). It is emphasized that sensitivity analysis also enhances model understanding and enables model improvement.

\subsection{Limitations}

One issue is addressed related to the quantitative evaluation as described above. It is not feasible to precisely predict the effect of a proposed shape grammar rule, since transport networks are rarely identical, especially when considering flows, and since the problem of network improvement is $\mathscr{N} \mathscr{P}$-hard (Garey and Johnson 1979). This limitation has the following consequences. Given an optimal infrastructure improvement recommendation for a specific transport network, this recommendation is not transferable to another, even similar network, claiming an identical effect on the network and its use. The reason for this intransferability is due to the complexity of network design. Therefore, uncertainties will remain when specifying shape grammar rules, and, due to the complexity of urban network design, these uncertainties cannot be eliminated. Here, it is proposed that these uncertainties are approached with a syntax-semantics methodology, explained in Section 2.4. The methodology is based on pairs of rules and corresponding assumptions, which means that every rule refers to specific assump- 
tions. An assumption, on which the rule relies, is defined within the semantics, serving as background information about the designated shape grammar rules. Figure ?? visualized the language definition, referring to the syntax-semantics approach and the rule-assumption pair.

Obviously, the methodology should remain as general as possible regarding the design and evaluation of shape grammar rules to allow for a larger potential application field and fewer restrictions in applications. Planners might be able to apply planning rules more often. Generalization implies fewer specific assumptions that might narrow down the set of potential networks suitable for application. Therefore, only essential network components are considered to shed light on the most relevant network design aspects. Moreover, reliability analysis increase the application range, as discussed above.

In the following, it is assumed that mathematical models are able to evaluate complex transport network dependencies, such as network flows or accessibility. Moreover, mathematical network models enable a specific focus on certain network design components and their interactions. Additionally, it is assumed that certain shape grammars can be implemented in network models.

\section{Example shape grammar assessment for urban boulevard designs}

The following example illustrates the general methodological approach elaborated above about shape grammar assessments. The example covers the design of boulevards deployed in large cities around the world. Often, the boulevard is embedded in a local transport network.

Boulevards also provide characteristics for through traffic infrastructure. Obviously, through traffic can be handled in different ways: totally separated from local traffic or fully integrated in the local transport network, such as the boulevard network.

This section aims at an increasing understanding of boulevards, their characteristics, and their potential impacts in various (un-)congested network states. The impacts of boulevards are quantitatively estimated based on the explained model and objective functions below. Different shape grammars are applied for the boulevard design and are compared to networks without a boulevard with regards to efficiency measures.

\subsection{Objective and application specifications}

This paper distinguishes between artificially generated network models and real-world networks. Characteristics of real-world networks are essential to evaluate past developments. For example, Cardillo et al. (2006) and Strano et al. (2012) evaluated real-world networks and past network developments such as densities and lengths. However, the main focus of this paper relies on artificially generated networks and network models. Artificial networks enable the investigation and evaluation of specific network designs based on well-known network and transportation characteristics and finally the extraction of shape grammar rules. Relevant aspects of network designs can be crystallized and explained on artificial networks and their evaluations, while excluding the complexity and size of a real-world network. Artificial networks are able to ignore the politically and historically driven network design and construction decisions that occur in real-world networks. Moreover, topology, road, and intersection types can be exchanged for evaluation. And still, the resulting network characteristics remain comparable with characteristics of real-world networks due to empirically evaluated and consistent models and parameters (e.g., turn delays).

The application specifications include a featureless plane to avoid biases due to historical design decisions, and terrain. The featureless plane is a square of either 2 -by- 2 or $3-b y-3 \mathrm{~km}^{2}$ with a grid network of $100 \mathrm{~m}$ block size ( 400 or 900 blocks in total), similar to Yerra and Levinson (2005), Vitins et al. (2013), and van Nes (2003). The modeled multiway boulevard is situated in the center of the network, and has a high-capacity two-way center road and parallel minor one-way roads on both sides for access (Figure 5(a)). Four boulevard types are proposed in the following differing in the intersection design for the major center road (Figure 5(b)-Figure ??). 


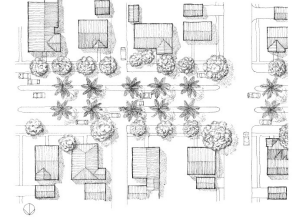

(a) Sacramento, San Francisco Boulevard (Ja-(b) Type 1, according to Figure 5(a), but with cobs et al. 2002, p.197).

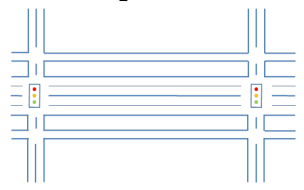

(c) Type 2, with signalized intersections (sim-(d) Type 3, with reduced number of conilar to Figure 5(b)), but improved pedestrian access without intermediate access roads.

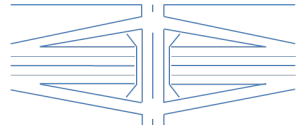

(e) Type 4, with multilevel diamond at the center road, requiring additional space, or construction on a lowered level.

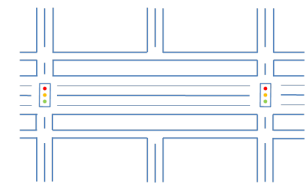

higher road capacities.

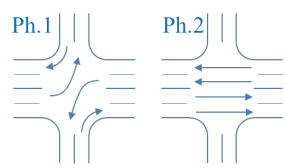

flict points at the center road intersection, with only two phases (Ph.1 and Ph.2), prohibiting direct boulevard crossing.

Figure 5: Boulevard designs

Type 1: Signalized intersections are located on the center road (Figure 5(b)), according to Figure 5(a), but with higher center road capacities.

Type 2: Signalized intersections are located on the center road with longer parallel minor roads for pedestrians and retail without intermediate access roads (Figure 5(c).

Type 3: Signalized intersections are located on the center road, but with reduced number of conflict points and with only two phases (Ph.1 and Ph.2), prohibiting direct boulevard crossing (Figure 5(d)).

Type 4: Multilevel intersections of diamond shape to increase safety and efficiency, but require additional space, or construction on a lower level (Figure ??).

The boulevard center line can be accessed and crossed every second block (similar to Avenue Foch in Paris, Passeig de Gràcia and Diagonal in Barcelona, and Ocean Parkway in Brooklyn), in contrast with the remaining network, which has homogeneously distributed blocks embedded in a grid network with right-of-way intersections. Right-of-way intersections are implemented in the remaining network due to low turn delays up to medium traffic volumes. We intended to include high-capacity roundabouts as a fifth type, similar to Paris, but the lack of consistent norms for high-capacity roundabouts (>2 lanes) made evaluation impossible.

\subsection{Objective functions}

The objective is to assess the effects of a boulevard from a transport planning perspective. The degree and even the direction of the outcome is unclear when designing a boulevard. On one hand, the boulevard might either reduce the overall network capacity due to turn restrictions and high signal delays. On the other hand, the boulevard can increase overall network capacity due to additional lane miles. Additionally, the costs can exceed user benefits, even over time.

Three objective functions are used to cover changes in user costs, spatial impact, and external costs.

User costs include monetarized travel time as a function of distance (Hess et al. 2008), including operating costs (VSS 2006c), and relate to the general cost-benefit analysis (CBA). 
Table 8: External costs calculation for cars, excluding tax revenue due to additional gasoline consumption, according to the Swiss cost-benefit norms.

\begin{tabular}{|c|c|c|c|}
\hline & Measure & Value & Source \\
\hline Noise & Decibel & $0.0140[\mathrm{sFr} . / \mathrm{veh} . \mathrm{km}]$ & VSS (2006b) \\
\hline \multirow[t]{3}{*}{ Air pollution } & Particulate matter & $3.55 \cdot 10^{-2}[\mathrm{sFr} . / \mathrm{veh} . \mathrm{km}]$ & VSS (2006b) \\
\hline & Nitrogen oxide & $1.00 \cdot 10^{-2}[\mathrm{sFr} . / \mathrm{veh} . \mathrm{km}]$ & VSS (2006b) \\
\hline & Zinc & $1.30 \cdot 10^{-3}[\mathrm{sFr} . / \mathrm{veh} . \mathrm{km}]$ & VSS (2006b) \\
\hline Climate effect & $\mathrm{CO}_{2}$ equivalent & $\begin{array}{r}8.40 \cdot 10^{-3}[\mathrm{sFr} . / \mathrm{veh} . \mathrm{km}] \\
(\text { values for } 2010)\end{array}$ & VSS (2006b) \\
\hline \multirow[t]{3}{*}{ Accidents } & Roads & $0.1741[\mathrm{sFr} . / \mathrm{veh} . \mathrm{km}]$ & VSS (2010) \\
\hline & Signal light & $0.1142[\mathrm{sFr} . / \mathrm{veh}]$. & VSS (2010) \\
\hline & Right-of-way & 0.1697 [sFr./veh.] & VSS (2010) \\
\hline
\end{tabular}

Regarding spatial economics, an accessibility measure is proposed, which is widely used in transport and economics. The theory is based on Rice et al. (2006), who stated that doubling the working population proximate to an area raises productivity. Additionally, Porta et al. (2008) showed correlations between a centrality measure and the distribution of commercial and service activities. Levinson and Huang (2012) summarized the theory of economies of agglomerations.

Accessibility complements the user-cost-based measure above. Accessibility is defined here as the logsum term of a choice model giving the expected maximum utility of all alternatives (Ben-Akiva and Lerman 1985), as applied in multiple Swiss studies (Axhausen et al. 2008). The accessibility is weighted with the number of people benefiting from it, and therefore is also called person-weighted accessibility (similar to Levinson et al. 2014). Equation (1) defines the accessibility measure used in this research. Land-use dynamics are ignored, which also affect traffic flows, and only calculate the initial effect of a boulevard.

$$
\text { Total Accessibility }=\sum_{\forall i} B_{i} \cdot \underbrace{\ln \left(\sum_{\forall j} X_{j} \cdot f\left(c_{i j}\right)\right)}_{\text {Accessibility of location } i}
$$

$X_{i}: \quad$ Attractiveness of location $i$ (here: sum of workplaces and residents).

$B_{i}$ : Weighting the accessibility (here: number of residents).

$f\left(c_{i j}\right)$ : Weighting function, dependent on the generalized costs of travel $c_{i j}$, here: $f\left(c_{i j}\right)=e^{-\beta c_{i j}}, \beta=0.2, c_{i j}=$ travel time.

Regarding the external costs, we considered a set of variables (Table 8). Jacobs et al. (2002) evaluated the safety of boulevard intersections. In general, boulevards seem not to be more dangerous compared to streets with comparable capacities or flows, according to an evaluation of empirical data (Jacobs et al. 2002). We therefore ignore safety changes due to the specific boulevard design. We exclude trucks and public transportation in the calculation of external costs.

Costs for construction vary considerably in existing data and are often not available in detail. We extracted the costs from Jack Faucet Associates (1991), Litman (2011), and Alam et al. (2005) and used these data for a rough CBA estimate below. A major arterial costs about $\$ 1.3$ million per lane/per $\mathrm{km}$ and a collector road costs $\$ 0.8$ million per lane/per $\mathrm{km}$ in a built-up area (year 2000), excluding land costs.

\subsection{Methodology}

Travel demand is uniformly spread in the area considered. Every block (400 or 900 in total depending on the network size) is modeled as a demand-generating node. Uniform demand distribution avoids a 
bias due to specific demand flows. The total travel demand is according to a dense four-story perimeter block development with courtyards in Zurich and comprises all travel purposes according to the census (Swiss Federal Statistical Office (BFS) 2012). Through traffic is ignored here. The determination of through traffic is very case-specific. Moreover, it is assumed that additional lanes on the major center road can cater to additional through traffic. The assumed block size of $100 \mathrm{~m}$ is based on Strano et al. (2012) and is similar to Manhattan, Bogotá, or other cities. For each block, the centroid is linked by access links to the nearest roads.

A high-resolution static model is deployed with detailed intersection delay calculations. Intersection types and turn delay calculations are calculated according to the HCM (Transportation Research Board 2010). The demand assignment is conducted with a Frank and Wolfe algorithm (Frank and Wolfe 1956). Synchronization of signals is approximated to account for the boulevard green wave. Vehicles do not have to stop at consecutive intersections when driving on the boulevard. This method assumes a perfect green wave without queue spillover. Convergence of the demand assignment is analyzed and stable according to Sheffi (1985).

\subsection{Effectiveness and elasticities}

Figure 6 depicts the travel distances and relative intersection delay as a function of the boulevard length $l[\mathrm{~m}]$. The reasons are threefold for increasing travel distances and decreasing relative intersection shares. Drivers remain longer on the boulevard due to its higher speed and lower intersection delays (green wave). However, drivers also reroute to avoid crossing the boulevard due to higher intersection delays at the boulevard crossings. Additionally, asymmetric travel behavior is observed due to higher left-turn delays on the boulevard compared to straight or right-turn delays.
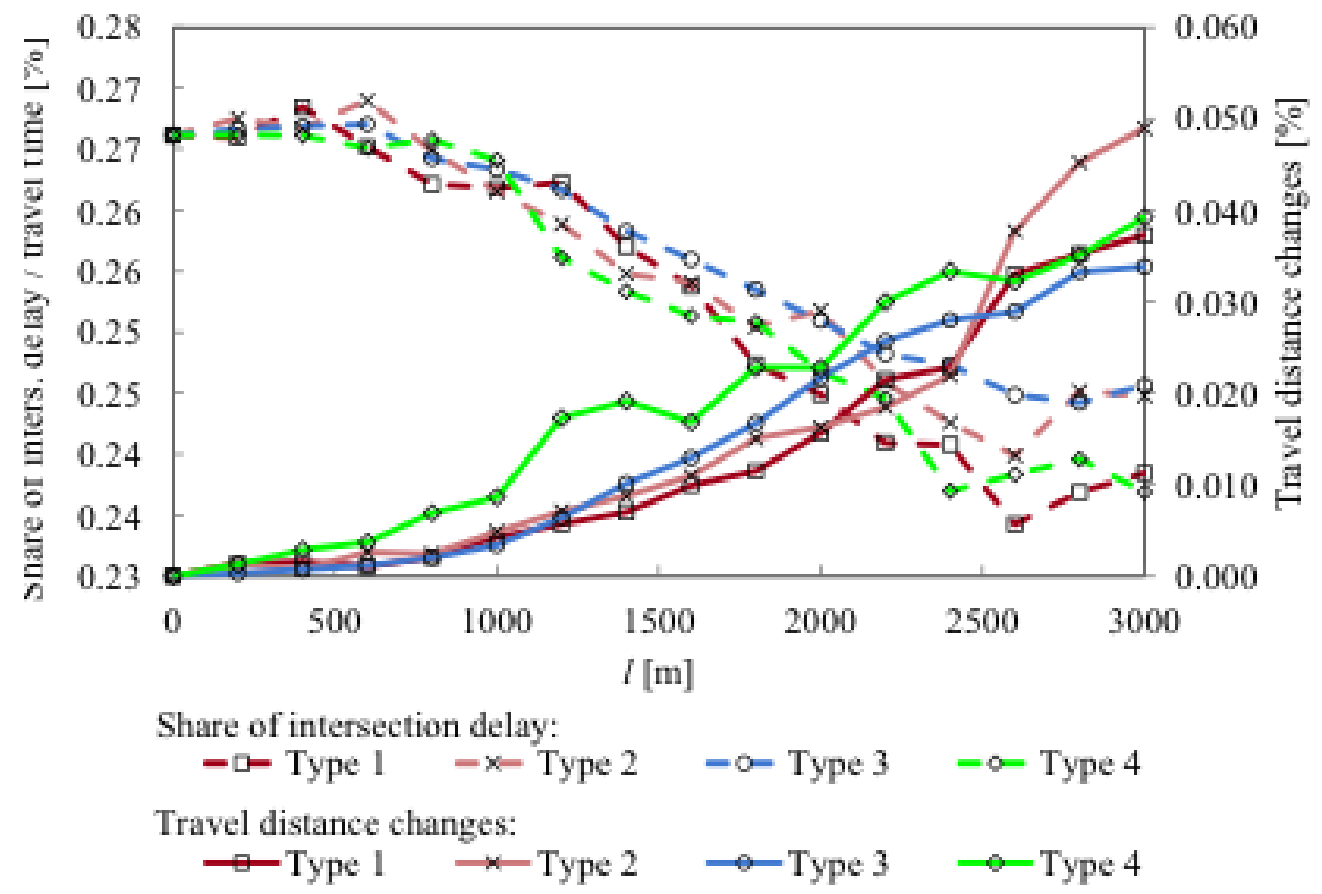

Figure 6: Average delays and travel distances for $3 \cdot 3\left[\mathrm{~km}^{2}\right]$ networks areas of all boulevard designs for peak hour traffic.

Figure 7.4 depicts the results of the evaluation for the three objective functions compared to networks without a boulevard. Therefore, the data points approximate $(x / y)=(0.0 / 0.0)$ at a boulevard length of zero meters. On the one hand, Figure 7.4 indicates considerable nonlinear trends especially for short and long boulevards, which complicates elasticity calculations. On the other hand, the resulting data in Figure 7.4 shows longer linear intervals, allowing for elasticity calculation based on linearity. 
Data are approximated with a polynomial function $f(l)$ to account for both effects. Polynomials of degree 3 can account for the nonlinear effect of the very long and short boulevards (see Figure 7.4) and, at the same time, reasonably approximate a linear interval. Therefore, polynomials with a degree of 3 are able to account for slope changes at both ends, avoid overfitting of the data points, and achieve a high fit $\left(\mathrm{R}^{2}\right)$. The highest slope values $f^{\prime \prime}\left(l_{\text {max }}\right)=0$ are determined based on polynomials of $s$-shapes like in Figure 7.4. A two-sided application range $\left\{l_{\text {min }}, l_{\text {max }}\right\}$ is proposed, in which values close to the highest slope values can be expected $\left(f^{\prime}\left(l_{\text {min }}, l_{\text {max }}\right)=f^{\prime}\left(l_{\text {max }}\right) \cdot \lambda\right)$. Therefore, an approximated elasticity $\epsilon^{s}$ is calculated for the subset $s$ of the data, which is inside the interval. Polynomials are approximated with Apache Commons (2013).

Table 9 summarizes the elasticities of the data for boulevard Type 1 with signalized intersections. $\epsilon^{s}$ is the elasticity within the application range. For example, travel time elasticity $\epsilon^{s, T}$ is calculated as $\epsilon^{s, T}=\frac{\delta t}{\delta l} \overline{\bar{t}}$ where $l$ is the length of the boulevard.

An increasing elasticity is shown at higher flows, especially for the 3 -by- $3 \mathrm{~km}^{2}$ networks. Additionally, the 3 -by- $3 \mathrm{~km}^{2}$ networks have higher values than the 2-by $2 \mathrm{~km}^{2}$ network, due to higher average travel distances. The minimum and maximum values of the application range $l_{\text {min }}-l_{\text {max }}$ increase for larger networks. There is evidence that the effect of larger boulevards can be approximated with functions of higher slopes. The polynomial approximation changes, as well as the $l_{\min }$ and $l_{\max }$ values, due to the higher slope and different polynomial approximation.

Table 9: Marginal costs, application range $l_{\text {min }}-l_{\text {max }}[\mathrm{m}]$ for $\lambda=0.8$, and elasticities for boulevards with signal lights (Type 1) of length $l$.

\begin{tabular}{|c|c|c|c|c|c|c|}
\hline \multirow[b]{3}{*}{ Marginal costs $\frac{\delta t}{\delta I}\left[\frac{s F r}{h \cdot m}\right]$} & \multicolumn{6}{|c|}{ Size of featureless plane $\left[\mathrm{km}^{2}\right]$} \\
\hline & & $2 \cdot 2$ & & & $3 \cdot 3$ & \\
\hline & $\frac{\delta t}{\delta I}$ & $\mathrm{R}^{2}$ & $l_{\min }-l_{\max }$ & $\frac{\delta t}{\delta I}$ & $\mathrm{R}^{2}$ & $\begin{array}{l}l_{\min }^{-} \\
l_{\max }\end{array}$ \\
\hline average daily traffic volumes & -0.3970 & 0.9965 & $320-1 ' 290$ & -1.067 & 0.9936 & $\begin{array}{l}610- \\
2^{\prime} 110\end{array}$ \\
\hline peak hour traffic volumes & -0.5630 & 0.9958 & $370-1 ’ 370$ & -1.282 & 0.9766 & $\begin{array}{l}970- \\
2 ' 270\end{array}$ \\
\hline $\begin{array}{l}2 \times \text { daily traffic volumes (for } \\
\text { sensitivity) }\end{array}$ & -0.7161 & 0.9933 & $440-1 ' 280$ & -1.377 & 0.9006 & $\begin{array}{r}\text { 1’010- } \\
\text { 2'240 }\end{array}$ \\
\hline $\begin{array}{l}\text { Monetarized travel time elasticities } \\
\epsilon^{s, T}=\frac{\delta t}{\delta L} \frac{\bar{L}}{\bar{t}} \text { for }\end{array}$ & & $\epsilon^{s, T}$ & & & $\epsilon^{s, T}$ & \\
\hline average daily traffic volumes & & 1.285 & & & 1.312 & \\
\hline peak hour traffic volumes & & 1.292 & & & 1.719 & \\
\hline $\begin{array}{l}2 \times \text { daily traffic volumes (for } \\
\text { sensitivity) }\end{array}$ & & 1.371 & & & 1.864 & \\
\hline
\end{tabular}

Table 10 compares different boulevard types, objective functions, and demand volumes (average, peak hour, $2 \mathrm{x}$ average for sensitivity), enabling future recommendations. Boulevards with signal lights at the major center road (Type 1) have the highest travel cost and accessibility elasticities. Boulevards with longer minor roads (Type 2) have the lowest travel cost and accessibility elasticities. Boulevards with conflict-free intersections (Type 3) and boulevards with multi-level intersections (Type 4) have lower elasticities compared to Type 1 ; values also differ in the size of the network. High $\mathrm{R}^{2}$ is calculated throughout the evaluations. 


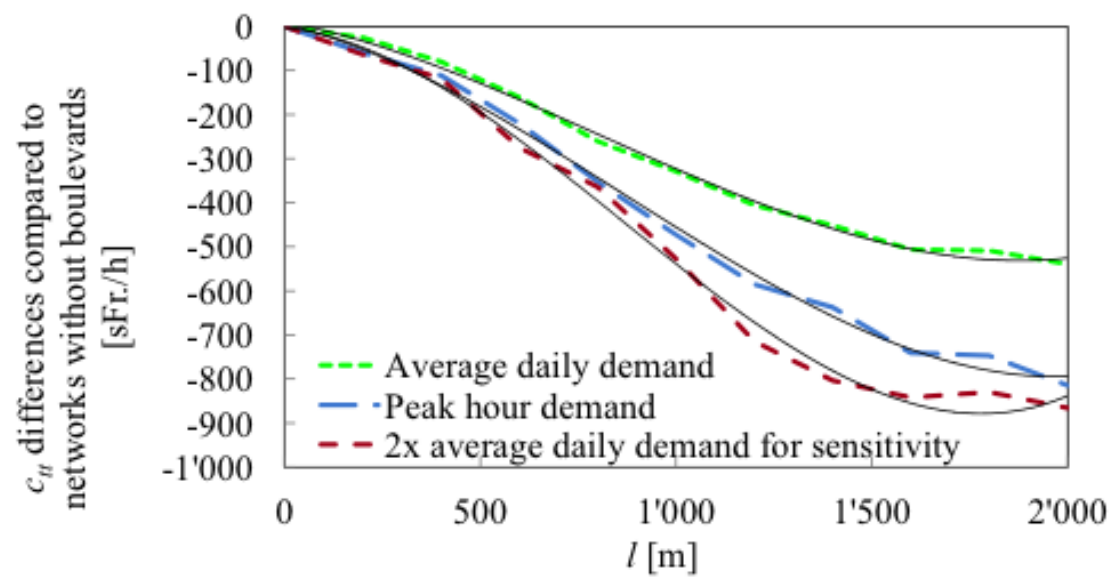

(a) Monetarized travel costs

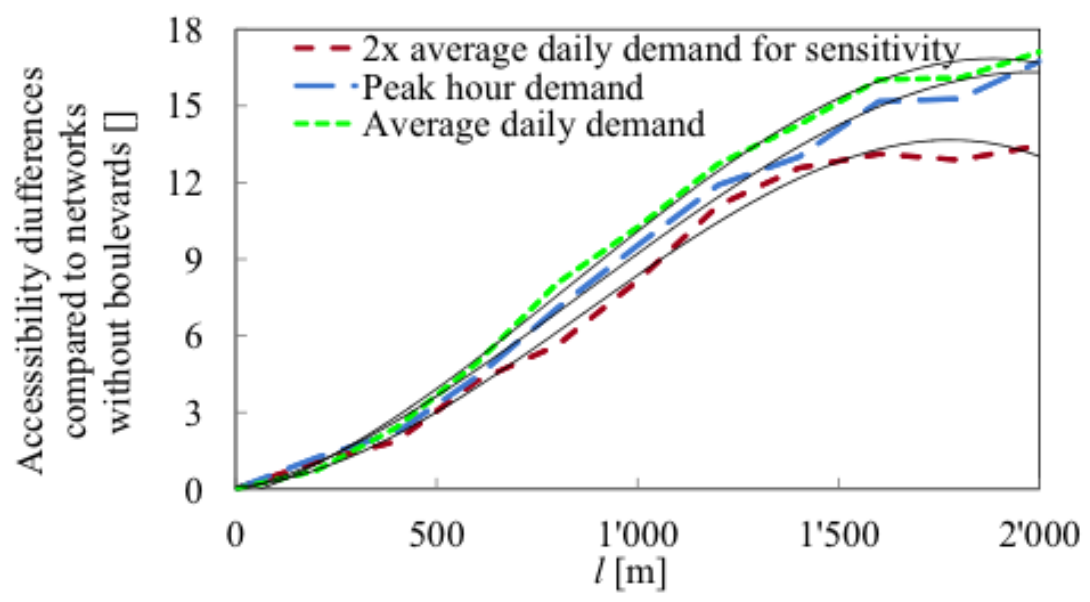

(b) Accessibility

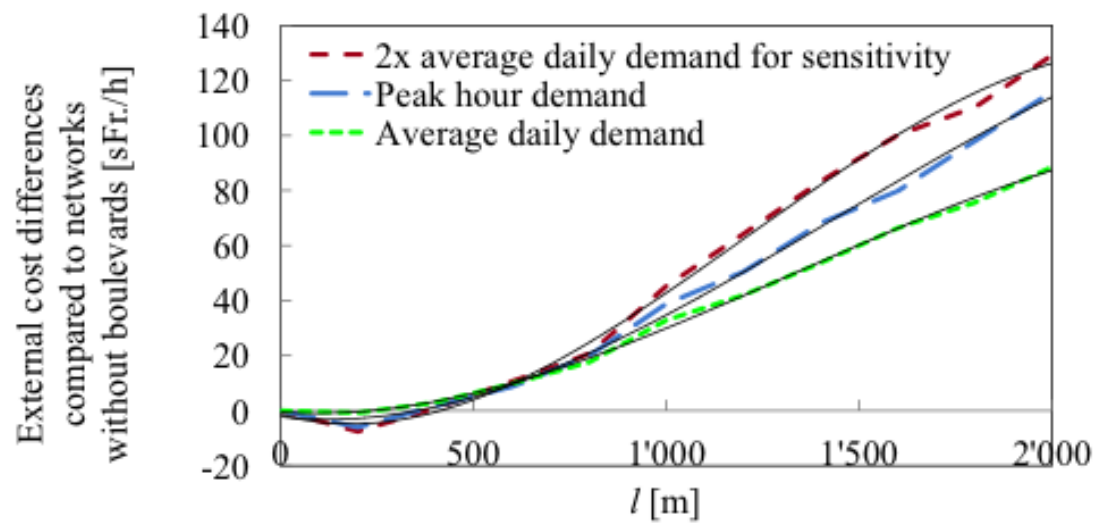

(c) External costs

Figure 7: Total monetarized travel time $\left(c_{t t}\right)$, accessibility and external effect changes for different boulevard lengths $l$ of Type 1 and networks of 400 blocks 
Table 10: Comparison of the elasticities $\epsilon^{s}$ for $\lambda=0.8$ and confidence of determination $R^{2}$ of all boulevard types; with $\epsilon^{s}$ values for different demand volumes $n$.

\begin{tabular}{lccrc} 
& \multicolumn{3}{c}{ Size of featureless plane $\left[\mathrm{km}^{2}\right]$} & $3 \cdot 3$ \\
Travel cost elasticities & $\min _{n}\left\{\epsilon_{n}^{s, T}\right\}, \max _{n}\left\{\epsilon_{n}^{s, T}\right\}$ & $\min _{n}\left\{R_{n}^{2}\right\}$ & $\min _{n}\left\{\epsilon_{n}^{s, T}\right\}, \max _{n}\left\{\epsilon_{n}^{s, T}\right\}$ & $\min _{n}\left\{R_{n}^{2}\right\}$ \\
\hline Type 1: Signal & & 0.9969 & $1.312,1.864$ & 0.9006 \\
Type 2: Signal (pedestrians) & & 0.9871 & $0.9425,1.301$ & 0.8442 \\
Type 3: Red. of conflict points & & 0.9948 & $1.302,1.582$ & 0.9945 \\
Type 4: Multilevel & & 0.9940 & $1.222,1.354$ & 0.9902 \\
\hline Accessibility elasticities & $\min _{n}\left\{\epsilon_{n}^{s, A}\right\}, \max _{n}\left\{\epsilon_{n}^{s, A}\right\}$ & $\min _{n}\left\{R_{n}^{2}\right\}$ & $\min _{n}\left\{\epsilon_{n}^{s, A}\right\}, \max _{n}\left\{\epsilon_{n}^{s, A}\right\}$ & $\min _{n}\left\{R_{n}^{2}\right\}$ \\
\hline Type 1: Signal & & 0.9930 & $1.360,1.920$ & 0.8970 \\
Type 2: Signal (pedestrians) & & 0.9863 & $0.8908,1.292$ & 0.8527 \\
Type 3: Red. of conflict points & & 0.9947 & $1.303,1.611$ & 0.9950 \\
Type 4: Multilevel & & 0.9937 & $1.271,1.382$ & 0.9898 \\
\hline External costs & $\min _{n}\left\{\epsilon_{n}^{s, E}\right\}, \max _{n}\left\{\epsilon_{n}^{s, E}\right\}$ & $\min _{n}\left\{R_{n}^{2}\right\}$ & $\min _{n}\left\{\epsilon_{n}^{s, E}\right\}, \max _{n}\left\{\epsilon_{n}^{s, E}\right\}$ & $\min _{n}\left\{R_{n}^{2}\right\}$ \\
\hline Type 1: Signal & & 0.9970 & $1.782,2.917$ & 0.9734 \\
Type 2: Signal (pedestrians) & & 0.9957 & $1.758,2.509$ & 0.9557 \\
Type 3: Red. of conflict points & & 0.9863 & $1.772,2.212$ & 0.9953 \\
Type 4: Multilevel & & 0.9973 & $1.252,1.638$ & 0.9787 \\
\hline
\end{tabular}

Table 10 additionally summarizes the external cost evaluations. Multilevel boulevards have the lowest external cost elasticities. The remaining boulevard types have higher cost elasticities but without a clear ranking order. Detailed evaluation showed that Type 1 and Type 2 have generally low external cost elasticities but increasing values for increasing traffic flows. Overall, it is observed that some external cost results could be approximated with other functions than polynomial functions of degree 3.

\subsection{Sensitivity analyses and evaluation}

Multiple causes are identified for increasing generalized travel costs in boulevard design despite the high boulevard capacity. Three situations possibly trigger an undesirable network state.

- Drivers reroute off the boulevard onto parallel roads as soon as the speed decreases on the boulevard compared to the parallel routes. Rerouting decreases the original functionality of the boulevard and its center road. Rerouting off the boulevard increases average travel costs of all drivers up to 9 percent due to the unused capacity of the empty boulevard and the congested boulevard crossings and parallel roads.

- Long boulevards separate urban space in two halves. This separation increases travel time considerably if the crossings have long waiting times or low capacity. The reduced number of crossings at boulevards ( 50 percent in our example compared to a regular grid) especially increases the chances of bottlenecks. Moreover, the feeder roads approaching the boulevard crossings get congested as well. High intersection density of the feeder roads near the boulevard also increases delays. Cars might drive around the boulevard to avoid congestion if the capacity of the intersections and feeder roads is insufficient.

- Drivers crossing the boulevard increase the delay for cars driving on the boulevard, due to the adaptive green times of signals on the boulevards. Due to adaptive green times, crossing flows increase their green time and at the same time reduce green time of the flows on the boulevard. This effect increases overall travel time on the boulevard and increase chances of rerouting onto parallel roads. 
Multiple solutions tackle the issues above. The boulevard axis needs to retain high flows during both uncongested and congested network states. Signals have longer turn delays due to the cycle characteristics. Therefore, travel speed has to be higher on the center road with signal settings maintaining the desired high flows (compared to the parallel minor roads).

Drivers might reroute onto parallel roads as soon as congestion is high enough on the boulevard to reach an equilibrium state in their route choice. Therefore, capacity should be rather high on boulevards to reduce delays and rerouting on parallel roads, as shown in many boulevards worldwide (Jacobs et al. 2002). Similarly, free-flow speeds on parallel roads might be reduced even more to prevent rerouting.

The functionality of a boulevard might be reduced through asymmetric travel demand, constructions, accidents, etc. Statistical analysis can estimate reliability and redundancy of the urban area considered (Bernard and Axhausen 2007). The evaluation showed that mainly the capacity of the signals are the limiting factor in boulevard design. High-capacity signalized intersections reduce the chance of a breakdown of the boulevard axis. The capacity should be large enough to supply a certain redundancy. Road capacity is not as limiting as signal capacity. Multiple and diverging approaching lanes can increase signal capacity for high flows.

Green waves reduce travel time on boulevards. However, it is found that green waves are not as influential as other infrastructure changes in the case of boulevards. Green waves only reduce uniform delay, which is low at high flows and with adaptive green times. Therefore, total travel costs merely decrease when implementing green wave synchronization.

The network sections adjacent to the boulevard are critical and relevant for the performance of the entire network. Flows crossing the boulevard reduce overall performance. If terrain barriers force traffic flows to cross the boulevard, the on- and off-flows at the intermediate intersections increase overall travel time and therefore reduce the flows on the boulevard itself. And if the flows of the boulevard are delayed, its major functionality is diminished.

The share of long-distance through traffic is ignored, which would be relevant for inbound or outbound traffic. The boulevard is assessed from a city perspective and did not consider external influences such as long-distance travel flow. Additional lanes could eventually allow for higher through traffic demand.

The following cost-benefit estimate holds for an approximately linear correlation of the boulevard length within the application range (see above) and travel costs $\left(t_{\text {absolut }} \propto l_{\text {Boulevard }}\right)$, and a low and conservative $\epsilon^{\text {s, travel cost }}$ value.

The benefit to cost ratio $\frac{b}{c}>1.0$ is reached after about 8 years, when assuming the costs above, maintenance (VSS 2008), lifespan, and discounted costs (VSS 2006a), but ignoring land acquisition.

For a time horizon of 100 years, the costs for land acquisition should not exceed $10,000 \mathrm{sFr} / \mathrm{m}_{\text {boulevard }}$

to reach a $\frac{b}{c}>1.0$. This low value is mainly due to discounted benefits and ongoing maintenance costs and medium dense urban densities.

Summing up, multiple issues occurred during modeling and evaluation, which are valuable for future design recommendations and the improvement of shape grammar rules. This additional information is added in the form of shape grammar rules, including application specifications summarized below.

\subsection{Shape grammar rules summary}

Sections 7.4 and 7.5 describe already various design recommendations based on the evaluation results. This section summarizes the results and findings according to the rule-semantic format proposed in Figure ?? and explained in Section 2.4, and therefore focusses on grammar rules and application specification, both listed in the following. It has to be added that grammar rules can be formulated in at least two different approaches. Stiny (1985) formulated grammar rules based on exact plans with precise definitions of shapes and elements, ending up in very precise floor plans. Unlike the precise defini- 
tions of Stiny (1985), Alexander et al. (1977) formulated the rules in a more descriptive manner based on sketches and broad design descriptions and recommendations. The following rules contain both approaches. Some rules can be stated more precisely, such as information about minimum boulevard length. Other rules are formulated in a more descriptive manner because they contain relative design statements. For example, the travel speed on the major center road should be higher than the parallel minor roads to avoid potential detours and negative effects on boulevard flows. This rule therefore only describes speed limits and avoids absolute specifications. In addition, some rules provide information about the conducted efficiency evaluations, which makes them look like observations or conclusive statements.

Rule set for boulevard design:

Rule 1: Boulevards should have a minimum length of $2-3$ blocks to achieve noticeable travel cost reduction and accessibility increases. Longer boulevards reduce travel costs and increase accessibility further. The target is $\geq 3$ blocks for boulevards in larger networks and higher average travel distance.

Rule 2: Boulevards with signals situated at the center road have the highest travel cost and accessibility elasticities $\epsilon^{s, T}, \epsilon^{s, A}$.

Rule 3: Travel speed on the boulevards has to be higher than on parallel roads, even under congested network conditions.

Rule 4: The capacity of the center road has to be high enough to accommodate the flows. At least two center lanes in each direction are advisable. The consequence of insufficient capacity on the center road would be rerouting onto parallel roads. On parallel roads, on-street parking spaces can reduce capacity and speed and therefore rerouting.

Rule 5: Boulevards reduce generalized travel costs of urban traffic if the major intersections at the center road provide enough capacity and low turn delays for the required flows. This holds also for the crossings of the boulevard, which might be bottlenecks for crossing traffic. At least 3 approaching lanes for the major intersections are advisable.

Rule 6: Boulevards have a benefit to cost ratio of $\frac{b}{c}>1.0$ only if the land prices are relatively low for land acquisition. Obviously, boulevards as proposed above should be planned in an early stage of urban design. If not, additional economic studies and effects (Venables 2007) have to be considered, which are beyond a standard cost-benefit procedure.

Corresponding application specifications:

The above rules are based on the following assumptions and evaluations. The application specification is described in Section 7.1 and 7.3 in detail. The major application specifications are outlined below:

- The following elasticities were estimated for boulevards with signals at the center road:

$-\epsilon^{s, \text { travel cost }} \simeq 1.3-1.9$, with higher $\epsilon^{\text {s, travel cost }}$ values at higher flows (e.g., peak hours).

$-\epsilon^{s, \text { accessibility }} \simeq 1.3-1.9$, with higher $\epsilon^{s, \text { accessibility }}$ values at higher flows.

- $\epsilon^{s, \text { external costs }} \simeq 1.6-2.9$, with higher $\epsilon^{\text {s, external costs }}$ values at higher flows.

- The results are based on a static model with detailed intersection delay formulae from the HCM (Transportation Research Board 2010) but ignore possible spillover effects of queues.

- Urban densities of a medium dense urban neighborhood are assumed in the base scenario (15,068 pers $/ \mathrm{km}^{2}$ and $6685 \mathrm{jobs} / \mathrm{km}^{2}$ ). Travel demand is estimated based on the Swiss micro census (Swiss Federal Statistical Office (BFS) 2012) in a simple and straightforward way with uniform demand distribution and including peak hour and reliability analysis. Due to the general uncertainty in planning and travel demand estimation, it is regarded as relevant to apply a comprehensive reliability analysis to gain information about changing travel demand and its effects.

- The results account for changes on the demand and supply side. Various urban densities are tested for robustness, as well as for changing infrastructure investments.

- Pedestrians, trucks, bicycles, and public transportation are not considered in the evaluation.

- The road lengths are based on average empirical data, as well as parcel shapes. 
- The boulevard is modeled in a gridiron network of $2-$ by $2 \mathrm{~km}^{2}$ and $3-$ by $3 \mathrm{~km}^{2}$, respectively.

\section{Conclusion}

This paper systematically reviews, classifies, and highlights the existing literature on shape grammars of urban and transport planning.

The comprehensive review reveals major articles and books published since the early and seminal results of Chomsky (1956). The contributions are classified according to their research fields, subjects, shape grammar objectives, and potential implementations. Moreover, synergies could be found between different languages, including logic, operations research, and linguistics.

The fundamental idea of shape grammars in fields such as architecture, geometry, or computer science matches the idea of shape grammars for urban network design. However, design rules (syntax) are insufficient to determine shape grammars. Application specifications (semantics) are needed to further specify the applications of rules and to increase the effectiveness after implementation. The application specifications describe the conditions under which the rules can be applied in practice as well as the effect of the application of the rules. Therefore, they should support practitioners in the application. It could be shown that the characteristics for meaningful applications can be determined for specific rules.

Drawing on these achievements, this paper proposes an assessment methodology for shape grammars enclosing potential objectives functions, such as generalized costs, an economical measure, or external effects. The authors posit that assessment is inevitable for shape grammar rule development. The potential of shape grammars can be fully exploited in a broader planning context when enhancing the effectiveness of grammar rule implementations through the proposed elasticity evaluations. An example application is provided on how to assess a certain shape grammar rule embedded in urban design. This paper demonstrates that elasticities are particularly instructive for future real-world applications, also due to the enhanced understanding of the rules.

This paper aims at increasing and more effective shape grammar applications and hopefully will nurture further contributions about grammar assessment and application in planning.

Future research work can take three directions. First, research might be required for future interdisciplinary assessment methodologies to cover the complex urban system as a whole. Second, our model is tested on a gridiron network so far. Other assessment methods could include different topologies and demand patterns, as well as stochastic assignments or large-scale microsimulation. Third, assessment results can be compared with real-world applications and data. 


\section{References}

AASHTO. 2004. A Policy on Geometric Design of Highways and Streets. American Association of State Highway and Transportation Officials, Washington, D.C.

Abady, M. and L. Gardelli. 1997. A Theory of Objects. New York: Springer.

Alam, M., D. Timothy, and S. Sissel. 2005. New capital cost table for highway investment economic analysis. Transportation Research Record, 1932:33-42.

Alexander, C., H. Heis, A. Anninou, and I. King. 1987. A New Theory of Urban Design. Oxford: Oxford University Press.

Alexander, C., S. Ishikawa, and M. Silverstein. 1977. A Pattern Language: Towns, Buildings, Construction. Oxford: Oxford University Press.

American Planning Association. 2006. Planning and Urban Design Standards. Hoboken: John Wiley $\&$ Sons.

Apache Commons. 2013. Commons Math 3.2. webpage. Accessed 2013/11/22, URL http: //commons.apache.org/proper/commons-math/.

Axhausen, K. W., C. Dolci, P. Fröhlich, M. Scherer, and A. Carosio. 2008. Constructing time-scaled maps: Switzerland from 1950 to 2000. Transport Reviews, 28(3):391-413.

Batty, M. 2005. Cities and Complexities. Cambridge: MIT Press.

Batty, M. 2008. The size, scale, and shape of cities. Science, 319(5864):769-771.

Beirão, J. N. 2012. CItyMaker - Designing Grammars for Urban Design, Architecture and the Built Environment. Ph.D. thesis, Delft University of Technology, Delft.

Ben-Akiva, M. E. and S. R. Lerman. 1985. Discrete Choice Analysis: Theory and Application to Travel Demand. Cambridge: MIT Press.

Bernard, M. and K. W. Axhausen. 2007. A highway design concept based on probabilistic operational reliability. In WCTRS, ed., 11th World Conference on Transportation Research. Berkeley: World Conference on Transport Research Society (WCTRS).

Bhat, C. R. and J. Y. Guo. 2007. A comprehensive analysis of built environment characteristics on household residential choice and auto ownership levels. Transportation Research Part B: Methodological, 41(5):506-526.

Bramley, G. and S. Power. 2009. Urban form and social sustainability: the role of density and housing type. Environment and Planning B, 36(1):30-48.

Caneparo, L., M. Collo, A. Montuori, and S. Pensa. 2007. Urban generator. In CAADFutures, ed., 12th CAADFutures Conference. Sydney.

Cardillo, A., S. Scellato, V. Latora, and S. Porta. 2006. Structural properties of planar graphs of urban street patterns. Physical Review E, 73(6):1-8.

Chomsky, N. 1956. Three models for the description of language. IEEE Transactions on Information Theory, 2(2):113-123.

Chomsky, N. 1959. On certain formal properties of grammars. Information and Control, 2(2):137167.

Clark, J. and D. A. Holton. 1991. A first look at graph theory. Teaneck: World Scientific.

CNU. 2012. Sustainable Street network Principles. Congress for the New Urbanism, Chicago.

Coates, P. 2010. Programming Architecture. London: Routledge.

Copper Marcus, C., C. Francis, and R. Russell. 1998. Urban plazas. In C. Copper Marcus and C. Francis, eds., People Places, pp. 13-84. New York: John Wiley \& Sons.

Courtat, T., C. Gloaguen, and S. Douady. 2011. Mathematics and morphogenesis of cities: A geometrical approach. Physical Review E, 83(3):1-12.

Cowan, R. 2002. Urban Design Guidance: Urban Design Frameworks, Development Briefs and Master Plans. London: Thomas Telford Publishing.

Duany, A., S. Sorlien, and W. Wright. 2009. SmartCode Version 9.2. Ithaca: New Urban News Publications Inc. 
Duarte, A., J. M. Rocha, and G. D. Soares. 2007. Unveiling the structure of the marrakech medina: a shape grammar and an interpreter for generating urban form. Artificial Intelligence for Engineering Design, Analysis, and Manufacturing, 21(4):317-349.

Duarte, J. P., J. N. Beirão, N. Montenegro, and J. Gil. 2012. City induction: A model for formulating, generating, and evaluating urban designs. In S. Müller Arizona, G. Aschwanden, J. Halatsch, and P. Wonka, eds., Digital Urban Modeling and Simulation, pp. 79-104. Berlin: Springer.

Dutton, J. A. 2000. New American Urbanism. Milan: Skira.

Erath, A., J. Birdsall, K. W. Axhausen, and R. Hajdin. 2009. Vulnerability assessment of the Swiss road network. Transportation Research Record, 2137:118-128.

ESRI. 2012. CityEngine. webpage. URL http://www.esri.com/software/cityengine/.

Estrada, M., M. Roca-Riu, H. Badia, F. Robuste, and C. F. Daganzo. 2011. Design and implementation of efficient transit networks: Procedure, case study and validity test. Transportation Research Part A: Policy and Practice, 45(9):935-950.

Ewing, R. and R. Cervero. 2010. Travel and the built environment. Journal of the American Planning Association, 76(3):265-294.

Fagin, R. 1974. General first-order spectra and polynomial-time recognizable sets. In R. M. Karp, ed., Complexity of Computation, pp. 43-73. Providence: Society for Industrial and Applied Mathematics (SIAM).

FGSV. 2008. Richtlinien für integrierte Netzgestaltung. Norm 121, Forschungsgesellschaft für Straßen- und Verkehrswesen, Cologne.

Fleisher, A. 1992. grammatical architecture? Environment and Planning B, 19(2):221-226.

Frank, M. and P. Wolfe. 1956. An algorithm for quadratic programming. Naval Research Logistics Quarterly, 3:95-110.

Friedman, D. P., M. Wand, and C. T. Haynes. 1992. Essentials of Programming Languages. Cambridge: MIT Press.

Garey, M. R. and D. S. Johnson. 1979. Computers and Intractability - A Guide to the Theory of NPCompleteness. San Francisco: W.H. Freeman and Company.

Geddes, N. M. B. 1939. To new horizons. In World's Fair. New York.

Gil, J. and S. Read. 2012. Measuring sustainable accessibility potential using the mobility infrastructure's network configuration. In P. U. C. de Chile, ed., 8th International Space Syntax Symposium, pp. 1-19. Santiago de Chile.

Goldberg, D. E. 2002. The Design of Innovation. Dordrecht: Kluwer.

Goodwin, P., J. Dargay, and M. Hanly. 2004. Elasticities of road traffic and fuel consumption with respect to price and income: A review. Transport Reviews, 24(3):275-292.

Haas, T. 2008. New Urbanism and Beyond. New York: Rizzoli.

Hackney, J. K., M. Bernard, S. Bindra, and K. W. Axhausen. 2007. Predicting road system speeds using spatial structure variables and network characteristics. Journal of Geographical Systems, 9(4):397417.

Heisel, F. and E. Yitbarek. 2013. Building laws for alternative materials: A shift towards function and performance-based building permits. Construction Ahead, Constructing Alternatives Part II, 13:10-12.

Helbing, D. 2013. Globally networked risks and how to respond. Nature, 497(7447):51-59.

Hess, S., A. Erath, and K. W. Axhausen. 2008. Estimated value of savings in travel time in Switzerland: Analysis of pooled data. Transportation Research Record, 2082:43-55.

Hillier, B., A. Leaman, P. Stansall, and M. Bedford. 1976. Space syntax. Environment and Planning $B, 3(2): 147-185$.

Hillier, F. S. and G. J. Lieberman, eds. 2005. Introduction to Operations Research. New York: McGrawHill.

IHT. 1997. Transport in the Urban Environment. Institution of Highways and Transportation, London. 
Jack Faucet Associates. 1991. The highway economic requirements system technical report; prepared for highway needs and investment branch. Technical report, Federal Highway Administration, Washington, D.C.

Jacobi, M., J. Halatsch, A. Kunze, G. Schmitt, and B. Turkienicz. 2009. A grammar-based system for the participatory design of urban structures. In CIGD, ed., 13th Congreso Iberoamericano de Gráfica Digital. Sao Paolo.

Jacobs, A., E. MacDonald, and Y. Rofé. 2002. The Boulevard Book. Cambridge: MIT Press.

Johnson, D. S., J. K. Lenstra, and A. H. G. Rinnooy Kan. 1978. The complexity of network design problem. Networks, 8(4):279-285.

Kaisersrot. 2011. Kaisersrot - Solutions you cannot draw. webpage. URL http://www.kaisersrot.com.

Keirstead, J. and N. Shah. 2011. Calculating minimum energy urban layouts with mathematical programming and monte carlo analysis techniques. Computers, Environment and Urban Systems, 35(5):368-377.

Kleijnen, J. P. C. 2008. Design and Analysis of Simulation Experiments. New York: Springer.

König, R. and D. Müller. 2011. Cellular-automata-based simulation of the settlement development in vienna. In A. Salcido, ed., Cellular Automata - Simplicity Behind Complexity, pp. 23-46. Rijeka: Intechopen.

Koning, H. and J. Eizenberg. 1981. The language of the prairie: Frank lloyd wright's prairie houses. Environment and Planning B, 8(3):295-323.

Lämmer, S., B. Gehlsen, and D. Helbing. 2006. Scaling laws in the spatial structure of urban road networks. Physica A: Statistical Mechanics and its Applications, 363(1):89-95.

LeBlanc, L. J. 1975. An algorithm for the discrete network design problem. Transportation Science, 9(3):183-199.

LeCorbusier. 1955. Oeuvre Complete. Zurich: Editions Girsberger.

Lehnerer, A. 2009. Grand Urban Rules. Rotterdam: NAI010 Publishers.

Levinson, D., D. J. Giacomin, and A. Badsey-Ellis. 2014. Accessibility and the choice of network investments in the london underground. In WSTLUR, ed., World Symposium on Transport and Land Use Research. Delft.

Levinson, D. and A. Huang. 2012. A positive theory of network connectivity. Transportation Research Part B: Methodological, 39(2):308-325.

Levinson, D., F. Xie, and N. M. Ocel. 2012. Forecasting and evaluating network growth. Networks and Spatial Economics, 12(2):239-262.

Lieb, C., F. Gubler, and H. Sommer. 2003. NISTRA: Nachhaltigkeitsindikatoren für Strasseninfrastrukturprojekte.

Litman, T. A. 2011. Transportation Cost and Benefit Analysis. Victoria: Victoria Transport Policy Institute.

Lord, E. A. and C. B. Wilson. 1984. The Mathematical Description of Shape and Form. New York: John Wiley \& Sons.

Lynch, K. 1960. The Image of the City. Cambridge: MIT Press.

Lynch, K. 1981. A Theory of Good City Form. Cambridge: MIT Press.

Lynch, K. 2001. Good City Form. Cambridge: MIT Press.

March, L. 1972. Elementary models of built forms. In L. Markin and L. March, eds., Urban Space and Structures, pp. 55-96. London: Cambridge University Press.

March, L. 1976. A boolean description of a class of built forms. In L. March, ed., The Architecture of Forms, pp. 41-73. London: Cambridge University Press.

Marshall, S. 2005. Streets and Patterns. London: Spon Press.

Mehaffy, M. W. 2008. Generative methods in urban design: A progress assessment. Journal of Urbanism, 1(1):57-75.

Michie, D. 1974. On Machine Intelligence. Edinburgh: Edinburgh University Press.

Mikoleit, A. and A. Puerckhauer. 2011. Urban Code. Zurich: GTA Verlag. 
Mitchell, W. J. 1990. The Logic of Architecture: Design, Computation, and Cognition. Cambridge: MIT Press.

Parish, Y. I. H. and P. Müller. 2001. Procedural modeling of cities. In E. Fiume, ed., Proceedings of ACM SIGGRAPH 2001, pp. 301-308. New York: ACM Press.

Porta, S., V. Latora, A. Cardillo, F. Wang, and S. Scellato. 2008. Street centrality and densities of retail and services in Bologna, Italy. Environment and Planning B, 36(3):450-465.

Prusinkiewicz, P. and A. Lindenmayer. 1996. The Algorithmic Beauty of Plants. New York: Springer.

Rice, P., A. J. Venables, and E. Patacchini. 2006. Spatial determinants of productivity: Analysis for the regions of great britain. Regional Science and Urban Economics, 36(6):727-752.

Saltelli, A., M. Ratto, T. Andres, F. Campolongo, J. Cariboni, D. Gatelli, M. Saisana, and S. Tarantola. 2008. Global Sensitivity Analysis: The Primer. Chichester: John Wiley \& Sons.

Sanni, T. and P. A. Albrantes. 2013. Estimating walking modal share: a novel approach based on spatial regression models and gis. Journal of Maps, 6(1):192-198.

Schirmer, P. M. and N. Kawagishi. 2011. Using shape grammars as a rule based approach in urban planning - a report on practice. In eCAADe, ed., 29th eCAADe Conference. Ljubljana.

Sheffi, Y. 1985. Urban Transportation Networks: Equilibrium Analysis with Mathematical Programming Methods. Englewood Cliffs: Prentice Hall.

Snellen, D., A. W. J. Borgers, and H. J. P. Timmermans. 2002. Urban form, road network type, and mode choice for frequently conducted activities: A multilevel analysis using quasi-experimental design data. Environment and Planning A, 34(7):1207-1220.

Sorkin, M. 1993. Local Code: The Constitution of a City at 42 N Latitude. New York: Princeton Architectural Press.

Southworth, M. and E. Ben-Joseph. 2003. Streets and the Shaping of Towns and Cities. Washington, D.C.: Island Press.

Stiny, G. N. 1985. Computing with form and meaning in architecture. Journal of Architectural Education, 39(1):7-19.

Stiny, G. N. 2000. Shape. Cambridge: MIT Press.

Stiny, G. N. and J. Gips. 1972. Shape grammars and the generative specification of painting and sculpture. In C. Freiman, ed., Information Processing 71, chapter 6, pp. 1460-1465. Amsterdam: NorthHolland.

Stiny, G. N. and W. J. Mitchell. 1978. The palladian grammar. Environment and Planning B, 5(1):518.

Stiny, G. N. and W.J. Mitchell. 1980. The grammar of paradise: On the generation of mughul gardens. Environment and Planning B, 7(2):209-226.

Strano, E., V. Nicosia, V. Latora, S. Porta, and M. Barthélemy. 2012. Elementary processes governing the evolution of road networks. Scientific Reports, 2:1-8.

Stübben, H. J. 1907. Der Städtebau. Stuttgart: Alfred Kröner Verlag.

Swiss Federal Statistical Office (BFS). 2012. Mobilität in der Schweiz - Ergebnisse des Mikrozensus Mobilität und Verkehr 2010. Swiss Federal Statistical Office (BFS), Neuchatel.

Synthicity. 2013. Synthicity. webpage. URL http://www.synthicity.com/.

Train, K. E. 1986. Qualitative Choice Analysis: Theory, Econometrics, and an Application to Automobile Demand. Cambridge: MIT Press.

Transportation Research Board. 2010. Highway Capacity Manual. Transportation Research Board, Washington, D.C.

University of Stuttgart. 2014. Developing harmonised european approaches for transport costing and project assessment (HEATCO). webpage. URL http://heatco.ier.uni-stuttgart.de/.

UrbanVision. 2012. Urbanvision home. software. URL http://www.cs.purdue.edu/cgvlab/urban/ urbanvision-system.html.

van Nes, R. 2003. Design of Multimodal Transport Networks. Ph.D. thesis, Technical University Delft, Delft. 
Vanegas, C. A., D. G. Aliaga, and B. Benes. 2010. Building reconstruction using manhattan-world grammars. In CUPUM, ed., 23th IEEE Computer Vision and Pattern Recognition. San Francisco: IEEE Computer Society.

Vanegas, C. A., D. G. Aliaga, B. Benes, and P. A. Waddell. 2009a. Interactive design of urban spases using geometrical and behavioral modeling. ACM Transactions on Graphics, 28(5):1-10.

Vanegas, C. A., D. G. Aliaga, P. Wonka, P. Müller, P. A. Waddell, and B. Watson. 2009b. Modeling the appearance and behavior of urban spaces. Computer Graphics forum, 28(2):1-18.

Venables, A. J. 2007. Evaluating urban transport improvements. Journal of Transport Economics and Policy, 41(2):173-188.

Vitins, B. J., I. Garcia-Dorado, C. A. Vanegas, D. G. Aliaga, and K. W. Axhausen. 2013. Evaluation of shape grammar rules for urban transport network design. In TRB, ed., 92nd Annual Meeting of the Transportation Research Board. Washington, D.C.: Transportation Research Board.

VSS. 1992. Projektierung, Grundlagen - Strassentypen. Norm SN 640 040b, Swiss Association of Road and Transport Professionals (VSS), Zurich.

VSS. 1994. Projektierung, Grundlangen. Norm SN 640 040b, Swiss Association of Road and Transport Professionals (VSS), Zurich.

VSS. 2006a. Diskontsatz in Kosten- Nutzen- Analysen im Verkehr. Norm SN 641 821, Swiss Association of Road and Transport Professionals (VSS), Zurich.

VSS. 2006b. Kosten-Nutzen-Analysen im Strassenverkehr: Externe Kosten. Norm SN 641 828, Swiss Association of Road and Transport Professionals (VSS), Zurich.

VSS. 2006c. Kosten-Nutzen-Analysen im Strassenverkehr; Grundnorm. Norm SN 641 820, Swiss Association of Road and Transport Professionals (VSS), Zurich.

VSS. 2008. Kosten-Nutzen-Analysen im Strassenverkehr: Kosten des betrieblichen Unterhalts von Strassen. Norm SN 641 826, Swiss Association of Road and Transport Professionals (VSS), Zurich. VSS. 2010. Kosten-Nutzen-Analysen im Strassenverkehr: Unfallraten und Unfallkostensätze. Norm SN 641 824, Swiss Association of Road and Transport Professionals (VSS), Zurich.

Wang, Y. and J. P. Duarte. 2002. Automatic generation and fabrication of designs. Automation in Construction, 11(3):291-302.

Watson, B., P. Müller, P. Wonka, C. Sexton, O. Veryovka, and A. Fuller. 2008. Procedural urban modeling in practice. IEEE Computer Graphics and Applications, 28(3):18-26.

Weber, B., P. Müller, P. Wonka, and M. Gross. 2009. Interactive geometric simulation of $4 \mathrm{~d}$ cities. Eurographics, 28(2):1-12.

Weis, C. 2012. Activity oriented modelling of short-and long-term dynamics of travel behaviour. Ph.D. thesis, ETH Zurich, Zurich.

Weis, C. and K. W. Axhausen. 2009. Induced travel demand: Evidence from a pseudo panel data based structural equations model. Research in Transport Economics, 25:8-18.

White, R., I. Uljee, and G. Engelen. 2012. Integrated modelling of population, employment and landuse change with a multiple activity-based variable grid cellular automaton. International Journal of Geographical Information Science, 26(7):1251-1280.

Wolfram, S. 2002. A New Kind of Science. Champaign Ill.: Wolfram Media.

World Bank. 2013. World bank data. webpage. URL http://data.worldbank.org.

Xie, F. and D. Levinson. 2007. Measuring the structure of road networks. Geographical Analysis, 39(3):336-356.

Xie, F. and D. Levinson. 2011. Evolving Transportation Networks. New York: Springer.

Yazar, T. and B. Colakoglu. 2007. A cad utility for shape grammars. In eCAADe, ed., 25th eCAADe Conference. Frankfurt.

Yerra, B. M. and D. Levinson. 2005. The emergence of hierarchy in transportation networks. Annals of Regional Science, 39(3):541-553.

Zimmermann, H.-J. 2008. Operations Research. Wiesbaden: Vieweg. 